\title{
Analysis of the Seismic Performance of Site-Bolted Beam to Column Connections in Modularized Prefabricated Steel Structures
}

\author{
Xuechun Liu, ${ }^{1,2,3}$ Xiaoxiong Cui, ${ }^{1}$ Zhiwei Yang, ${ }^{1}$ and Xinxin Zhan ${ }^{1}$ \\ ${ }^{1}$ Beijing Engineering Research Center of High-Rise and Large-Span Prestressed Steel Structures, Beijing University of Technology, \\ Beijing 100124, China \\ ${ }^{2}$ Beijing Key Laboratory of Earthquake Engineering and Structural Retrofit, Beijing University of Technology, Beijing 100124, China \\ ${ }^{3}$ Beijing Advanced Innovation Centre for Future Urban Design, Beijing 100044, China \\ Correspondence should be addressed to Xuechun Liu; liuxuechun@bjut.edu.cn
}

Received 10 March 2017; Revised 15 June 2017; Accepted 19 July 2017; Published 12 September 2017

Academic Editor: Michael Aizenshtein

Copyright (C) 2017 Xuechun Liu et al. This is an open access article distributed under the Creative Commons Attribution License, which permits unrestricted use, distribution, and reproduction in any medium, provided the original work is properly cited.

\begin{abstract}
This paper proposes a site-bolted connection that is suitable for modularized prefabricated steel structures. Excellent ductility is achieved by various structural measures. Six connection specimens with different parameters were subjected to quasi-static loading tests and finite element analysis (FEA) to determine the seismic performance of the proposed connection (e.g., hysteretic behavior, skeleton curve, ductility, and failure mode). The results of the tests and FEA showed that the connection underwent sufficient plastic deformation under cyclic loading and that its ultimate rotation angle could reach 0.09 rad. A clear plastic hinge formed on the beam before the connection failed, which suggests a ductile failure mode. The connection exhibited a wide hysteresis loop, which indicated good seismic performance. The results also showed that the connection does not slip under small earthquakes and could dissipate energy through slippage in the connection region under a moderate earthquake and through slippage in the connection region as well as plastic deformation at the beam end under a severe earthquake. The number of bolts was the main parameter that affected the seismic performance of the connection. The test and FEA results demonstrated that all six specimens had excellent seismic and ductile performance and an exceptional plastic rotation capacity.
\end{abstract}

\section{Introduction}

Before the 1990s, welded and bolted-welded connections were used extensively due to their high load-bearing capacity, stiffness, and cost-effectiveness. However, during the Northridge earthquake in the US and the Hanshin-Awaji earthquake in Japan, brittle fracture occurred in large numbers of these types of beam-column connections, which caused many high-rise steel structures to break and even collapse. Research has shown that the cracking of weld seams under cyclic loading will lead to damage to the connection and decreases in its stiffness and strength or even brittle failure of the connection. Since these two large earthquakes, researchers around the world have extensively studied and considerably improved welded connections [1-3]. Two types of measures are used to improve these connections, namely, reducing and strengthening measures, both of which are used to prevent brittle fractures in connections by shifting the plastic hinge away from the connecting weld seam. Naimi et al. [4] proposed a new bolted-welded connection with a reduced beam section and studied the effects of the beam depth and size of the beam web section on the connection performance. Li et al. [5] and Zhao et al. [6] studied a dog bone-shaped connection, a reduced connection with a long slot, and a bolted-welded connection with enlarged weld access holes and found that good weld quality is the main factor that prevents the brittle fracture of the connections. Chen et al. $[7,8]$ investigated the seismic performance of a bolted-welded beam end strengthened connection and proposed a method that strengthens the beam end by forming a plastic hinge in the beam away from the column face. The proposed method could effectively improve the seismic 
performance of beam-column connections. However, welded connections are disadvantageous due to the relatively high welding workload, complex welding process, and difficulty in ensuring the weld quality.

Site-bolted beam-column connections can be rapidly assembled on-site. They have a good plastic rotation capacity and excellent ductility and can dissipate seismic energy through slippage and plastic deformation that occurs in the joint region, which reduces damage to the structure by an earthquake. Astaneh-Asl [9] suggested that highstrength bolted beam connections should be designed to be semirigid and allowed to slip under high seismic loads, thereby dissipating seismic energy through slippage on the friction surfaces and compression between the bolts and the bolt hole walls. There are two types of site-bolted connections: rigid connections and variable stiffness connections. The calculations and analyses for rigid connections are simple, and they are used extensively. However, rigid connections require a large number of bolts. In comparison, variable stiffness connections have a higher energy dissipation capacity and require only a small number of bolts and thus are more economical. Rigid connections can be formed using T-stubs. Ribeiro et al. $[10,11]$ developed and improved an analytical procedure and investigated the mechanical behavior of $\mathrm{T}$ stub connections under impact loading using finite element analysis (FEA) and determined the damage scalar variable and equivalent plastic strain patterns of these connections. They compared the analytical results, three-dimensional (3D) finite element (FE) predictions, and experimental results for the connections and validated the experimental and analytical results. $\mathrm{Hu}$ et al. $[12,13]$ proposed a mechanical analysis model for T-stub connections and validated the model using both FEA and experiments.

End-plate connections are typical bolted connections with variable stiffness. Dessouki et al. [14], Prinz et al. [15], and Shi et al. [16] studied the seismic performance of endplate beam-column connections using experiments and FEA. Tsavdaridis and Papadopoulos [17] analyzed a large number of end-plate connections in which the beam was reduced by varying degrees along its length using FEA software and determined various mechanical properties of the connections under cyclic loading. Bai et al. [18] derived a revised design method for a new end-plate connection and compared the design equations specified in various codes. They analyzed a large number of models and demonstrated that their revised design equation is highly accurate for calculating the bending moment in bolts and end-plates allowing for prying force. Li et al. [19] studied the mechanical properties of flush end-plate composite joints under the combination of axial loading and elevated temperature conditions. Rahnavard et al. [20] studied the behaviors of common types of rigid connections, including connections with an endplate, connections with a bolted cover plate, and bolted $\mathrm{T}$ joints, under the effect of heat using numerical FE methods with the ABAQUS software. Fang et al. [21] proposed an extended end-plate connection that was formed using shape memory alloy bolts. They investigated various mechanical properties of this connection and provided a design method for it. Mirzaie Aliabadi et al. [22] introduced a new posttensioned T-stub connection (PTTC) for earthquakeresistant steel moment-resisting frames (MRFs) that consist of high-strength posttensioned (PT) strands and bolted Tstubs. They also investigated the theoretical behavior and proposed design methods based on parametric studies and comparisons with analytical results. Faridmehr et al. [23] proposed and studied a saddlebag connection. The results of tests and FEA showed that the proposed connection developed adequate catenary action, which is a fundamental criterion to prevent progressive collapse. Liu et al. proposed several new truss-square HSS column connections that are suitable for modularized high-rise steel structures, a fully welded connection [24] used in a module, a bolted-welded connection [25], and some fully bolted connections [2629] used for connecting different modules, and determined the seismic performance of the proposed connections from static and quasi-static loading tests and FEA. They [30] also designed and studied a modularized prefabricated steel frame structure with inclined braces in which the beam to column and column to column connections are made by bolts on-site. However, there are still a lack of connections, especially for modularized prefabricated structures. Hu et al. [31] studied the damage behavior, bearing capacity, plastic angle, ductility, and energy dissipation capacity of end-plate bolts with a cantilever beam that is prefabricated and welded to the column in the factory. Wang et al. [32] studied the seismic performance of a new type of prefabricated connection for a concrete-filled steel tubular column and steel beam. A lowcyclic loading test was carried out for joints with different parameters. Yu et al. [33] carried out a finite element analysis of the static and hysteretic behavior of a new type of beamcolumn prefabricated rigid joint. The failure modes and the effect of the number of bolts, the width and thickness of the cover plate, and the length of the cantilever section on the hysteresis performance under pseudostatic loading were studied. Jiang et al. [34] proposed a self-locking joint between concrete-filled steel tubular columns and steel girders for prefabricated structures and carried out a finite element analysis. Zhang et al. [35] carried out a monotonic loading test of a new type of joint between a square HSS column and truss beam used in a prefabricated structure and analyzed the stiffness, strength, and ductility of the joint. Ma et al. [36] carried out a low-cycle repeated loading test on bolted beam-column joints with a cantilever beam prefabricated and welded to the column in the factory, in which the bolt hole is a slot for assembly convenience.

These bolted connections showed good mechanical and seismic performance and rapid construction speed. However, more new types of bolted connections, especially for prefabricated structures, need to be proposed to accelerate the construction speed and ensure structural safety, and the bolt layout, bolt distance, bolt hole size, and connecting plate thickness need more study. This study investigates a sitebolted connection that connects an $\mathrm{H}$-section steel beam with a square HSS column. Six specimens were subjected to lowcyclic loading tests and FEA to study the seismic performance (hysteretic behavior, skeleton curve, ductility, rotation capacity, and stiffness degradation) of the connection and determine the key parameters that affect it. 


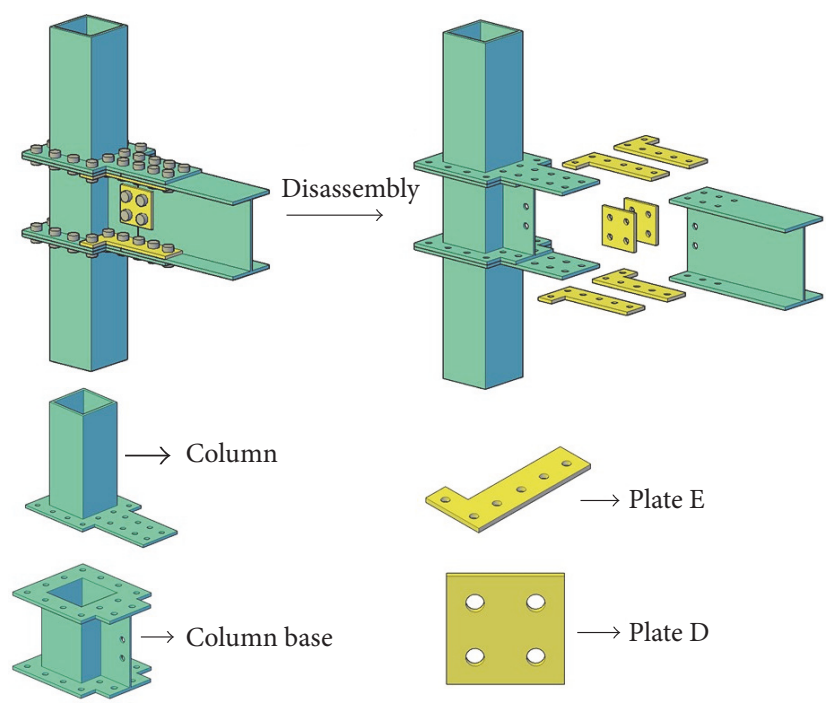

FIGURE 1: Assembly drawing of the connections.

\section{Connection Structure}

Figure 1 shows the connection that is investigated in this study, which is used to connect two beam slab modules. This connection is formed by connecting two columns with flanges at the end, a steel beam, a column base, and splint plates (plate E) with bolts. Each column with a flange is composed of a steel column and a flange equipped with a cover plate. The column base is composed of flanges, a short column, and a vertical stiffener. Bolt holes are prepared in the flanges, cover plates, beam flanges, and web plate. The parts are connected with high-strength bolts on-site. Using this connection, two adjacent beam slab modules, the column above the beam slab modules, and the column below them are connected. After assembly, the columns are filled with C60 concrete. The proposed connection can be used in a modularized high-rise steel structure composed of a foundation module, column modules, and beam slab modules (Figure 2). The foundation module is made of reinforced concrete. This fabricated process can be completed at the construction site or in the factory. The prefabricated upper structures are connected to the foundation by a connection preset on the foundation. The column modules are fabricated in the factory by welding square HSS columns to flanges with cover plates. A beam slab module is composed of column bases, beams, and concrete floor slabs. The floor slabs are poured in the factory and are connected to the beams by studs. Bolt holes are prepared in the column bases, flanges, and beams.

\section{Specimen Design}

3.1. Specimen Design. The site-bolted beam-column connection shown in Figure 2 was selected for this study. Two $200 \times$ $12 \mathrm{~mm}$ square HSS columns and a $300 \times 200 \times 8 \times 12 \mathrm{~mm} \mathrm{H}$ section steel beam were used to form each connection specimen. Except for the beam, which was composed of Q235B

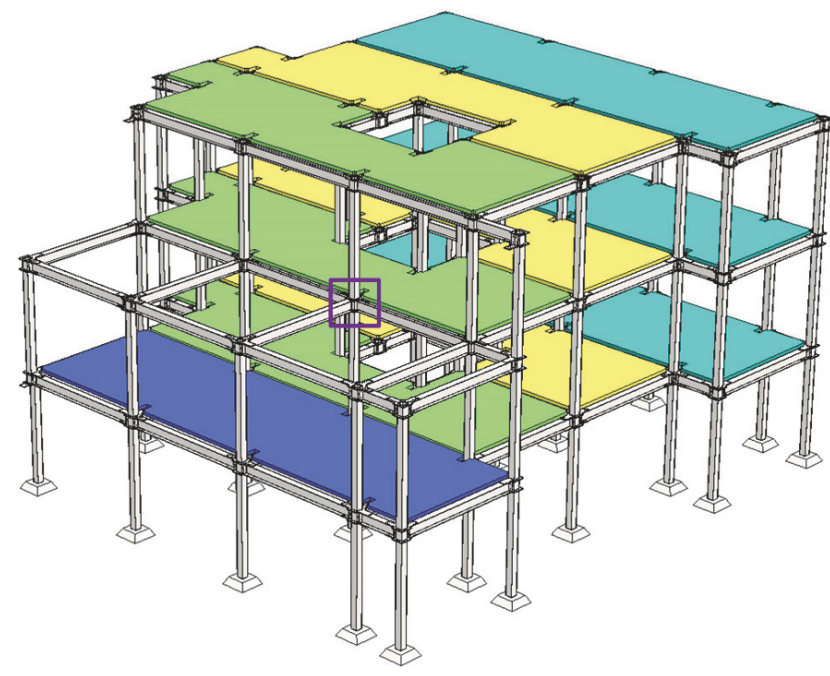

FIGURE 2: Structural system.

steel, all of the parts of each specimen were made of Q345B steel. The nominal yield strengths of Q235B and Q345B steels are $235 \mathrm{MPa}$ and $345 \mathrm{MPa}$, respectively. According to the Chinese Code for the Seismic Design of Buildings and Technical Specification for the Steel Structure of Tall Buildings, formula (1) is used to check the principle of strong column and weak beam $[37,38]$. The plastic section modulus of beam $W_{p b}$ is $843552 \mathrm{~mm}^{3}$ and that of column $W_{p c}$ is $637056 \mathrm{~mm}^{3}$. The axial force applied on the column is $500 \mathrm{k} \mathrm{N}, A_{c}$ is the area of the column, and $\eta$ is 1.1. The connection in this paper consists of two columns and one beam. The connection met formula (1) even before pouring the concrete, and the column will be stronger still after pouring concrete C60.

$$
\sum W_{p c}\left(f_{y c}-\frac{N}{A_{c}}\right) \geq \eta \sum W_{p b} f_{y b}
$$

Based on a previous study [39], the lengths between the respective inflection points were selected as the beam and column lengths of each specimen. Figure 3 shows the detailed dimensions of the connection. To study the effects of the number of bolts on the cover plate, the material grade of the type of plates $\mathrm{E}$, and the diameter of the bolt holes on the plates $\mathrm{E}$ on the connection's performance, two groups of specimens (M1 and M2) were designed by varying these parameters while keeping the cross-sections of the beam and columns constant. Groups M1 and M2 each contained three specimens (hereafter referred to as the M1 specimens and the M2 specimens, resp.). Each M1 specimen contained eight bolts on the cover plates, and each M2 specimen contained six bolts on the cover plates. Table 1 lists the basic parameters of the connections.

3.2. Testing of Material Properties. According to the specifications stipulated in Metallic Materials: Tensile Testing at Ambient Temperature [40], the steel plate specimens were fabricated using the same batch of steel plates that were used to produce the connection specimens to determine 


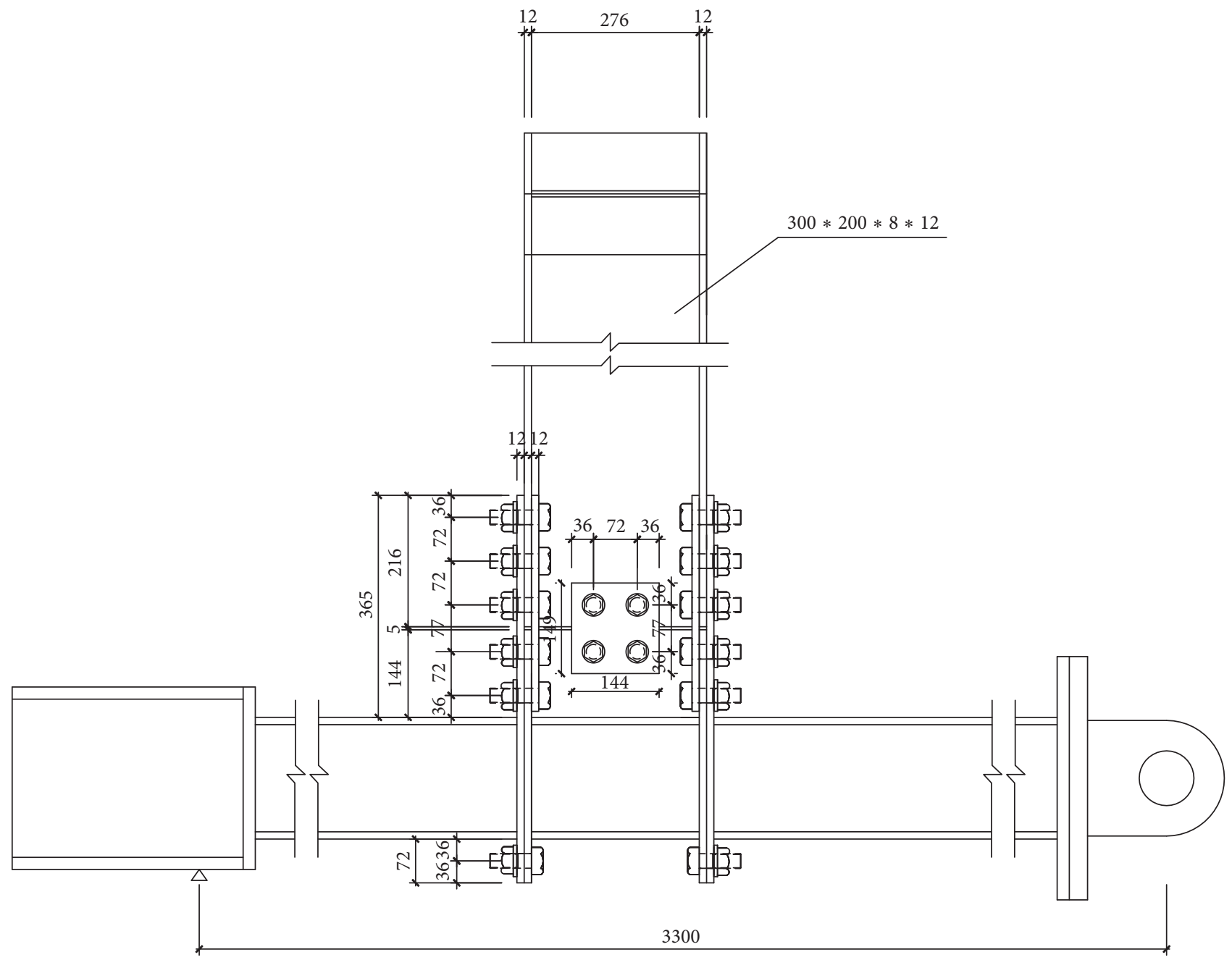

(a)

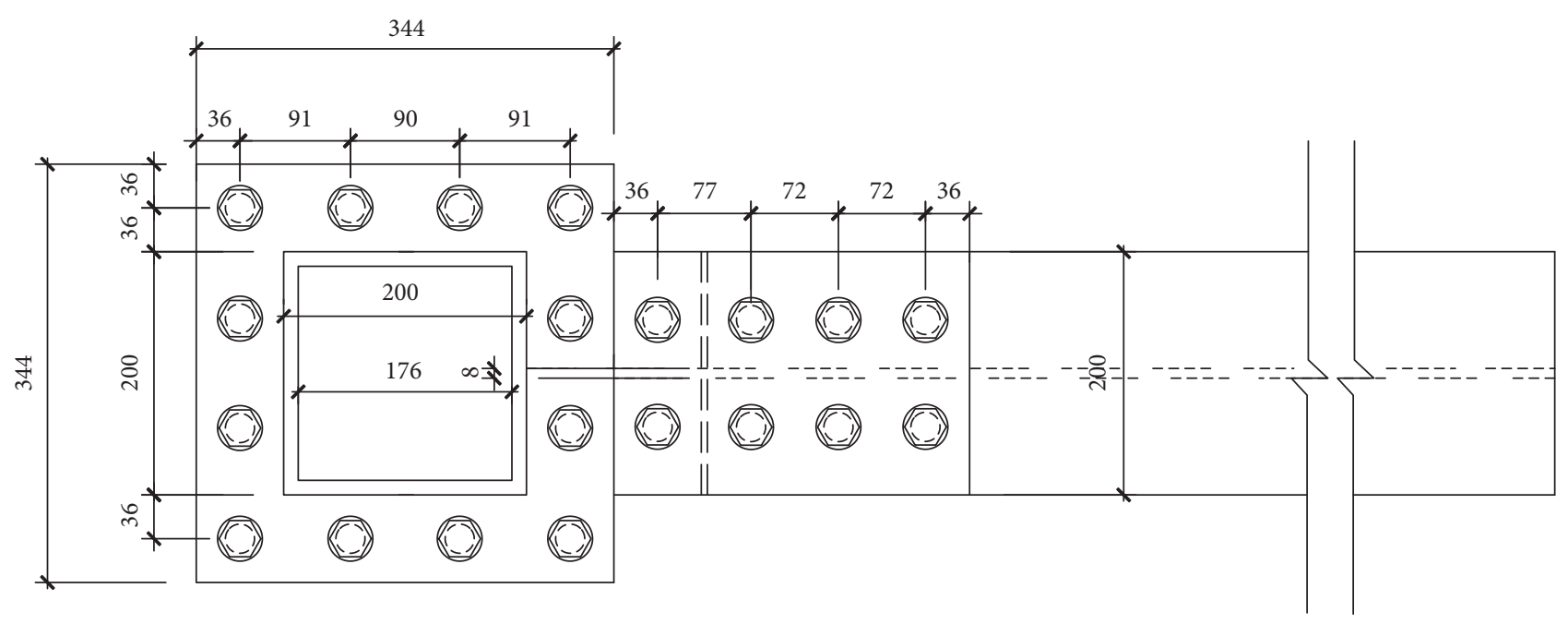

(b)

FIgURE 3: Details of the test specimens. (a) Elevation view. (b) Plan view. 
TABLE 1: Number and parameters of the specimens.

\begin{tabular}{|c|c|c|c|c|c|c|c|}
\hline \multirow{2}{*}{\multicolumn{2}{|c|}{ Specimen number }} & \multicolumn{2}{|c|}{ Flange } & \multicolumn{2}{|c|}{ Cover plate } & \multirow[b]{2}{*}{ Splint material } & \multirow{2}{*}{$\begin{array}{c}\text { Splint bolt hole } \\
\text { Diameter }\end{array}$} \\
\hline & & $\begin{array}{c}\text { Flange } \\
\text { thickness }\end{array}$ & Bolt & Bolt & $\begin{array}{c}\text { Number of } \\
\text { bolts }\end{array}$ & & \\
\hline \multirow{3}{*}{ M1 } & M1A & 12 & M20 & M20 & 8 & Q235 & 22 \\
\hline & M1B & 12 & M20 & M20 & 8 & Q195 & 22 \\
\hline & M1C & 12 & M20 & M20 & 8 & Q235 & 20 \\
\hline \multirow{3}{*}{ M2 } & M2A & 12 & M20 & M20 & 6 & Q235 & 22 \\
\hline & M2B & 12 & M20 & M20 & 6 & Q195 & 22 \\
\hline & $\mathrm{M} 2 \mathrm{C}$ & 12 & M20 & M20 & 6 & Q235 & 20 \\
\hline
\end{tabular}

TABLE 2: Material properties of the test specimens.

\begin{tabular}{|c|c|c|c|c|c|}
\hline \multicolumn{2}{|c|}{ Beam } & \multicolumn{2}{|c|}{ Column } & \multicolumn{2}{|c|}{ S10.9 bolt } \\
\hline Stress/MPa & Strain & Stress/MPa & Strain & Stress/MPa & Strain \\
\hline 285.4 & 0.00139 & 374.8 & 0.00171 & 995 & 0.0048 \\
\hline 309.7 & 0.01575 & 400.3 & 0.01514 & 1160 & 0.1375 \\
\hline 389 & 0.04291 & 448.2 & 0.05252 & 1160 & 0.1998 \\
\hline 420.4 & 0.07082 & 469.5 & 0.08688 & & \\
\hline 435.5 & 0.10091 & 479.4 & 0.12272 & & \\
\hline 441.2 & 0.12876 & 483.2 & 0.1601 & & \\
\hline 442.1 & 0.17911 & 484 & 0.19972 & & \\
\hline
\end{tabular}

their material properties. Table 2 lists the nominal stress and strain of the material property tests. The stress and strain will be transformed into real stress and strain for the finite element analysis. To measure the friction coefficient between the steel plates, high-strength bolted connection specimens were fabricated based on the requirements and methods stipulated in the Code for Acceptance of Construction Quality of Steel Structures [41]. The friction surfaces were subjected to a sandblasting treatment, and M20 grade 10.9 high-strength bolts made of $40 \mathrm{Cr}$ steel were used for the connection specimens. The test results showed that the specimens had a friction coefficient of 0.4 .

\section{Test Scheme}

4.1. Loading Device and Scheme. Each of the six specimens was subjected to a quasi-static loading test. The displacements of the inflection points of the columns were constrained, except for the displacement along the axis of the upper column. Lateral braces were used to constrain the out-ofplane movement of the beam. A constant axial pressure of $500 \mathrm{kN}$ was applied at the top of the column, and a lowfrequency cyclic load was applied to the end of the beam perpendicular to the axis of the beam. Figure 4 shows the loading device. A hydraulic servo system was used to apply the lowfrequency cyclic load. Referencing to the American Institute of Steel Construction's Seismic Provisions for Structural Steel Buildings [42], the loading sequence is simplified because the connection is in the elastic state even when the rotation angle is less than 0.01 and the number of cycles in the elastic phase is reduced. Then, a variable-amplitude displacementcontrol loading regime was employed, and the loading was controlled through the rotation angle. Figure 5 shows the loading regime.

4.2. Arrangement of Strain Gauges and Displacement Meters. As shown in Figure 6, the measuring points on the beamcolumn connection specimens were determined based on the connection design and the FEA results. To measure the strains in the plates in the joint region and in the areas under relatively high stress, the strain gauges were mainly placed in this region.

Displacement meters W1 were placed at the loading point at the beam end to measure the displacement of the beam end, and the arrangement of W1 is shown in Figure 4(b). Figure 6(a) shows the arrangement of the other displacement meters. The stands of displacement transducers WS and WN were placed on the beam flange, and the pointers were placed on the glass sheet at the front of the cover plate. Displacement meters WS were used to measure the slip distances between the cover plate and the upper beam flange, and WN were used to measure the slip distances between the cover plate and the lower beam flange.

\section{Test Process Analysis}

5.1. Testing Process for Specimen M1. Similar phenomena were observed when applying quasi-static cyclic loads to specimens M1A, M1B, and M1C. Figure 7 shows the failure mode of specimen M1A. A sound was heard when the rotation angle of specimen M1A reached $0.02 \mathrm{rad}$ cycles ( $32 \mathrm{~mm}$ in the positive direction and $37 \mathrm{~mm}$ in the negative direction) because slip occurred between the cover plates 


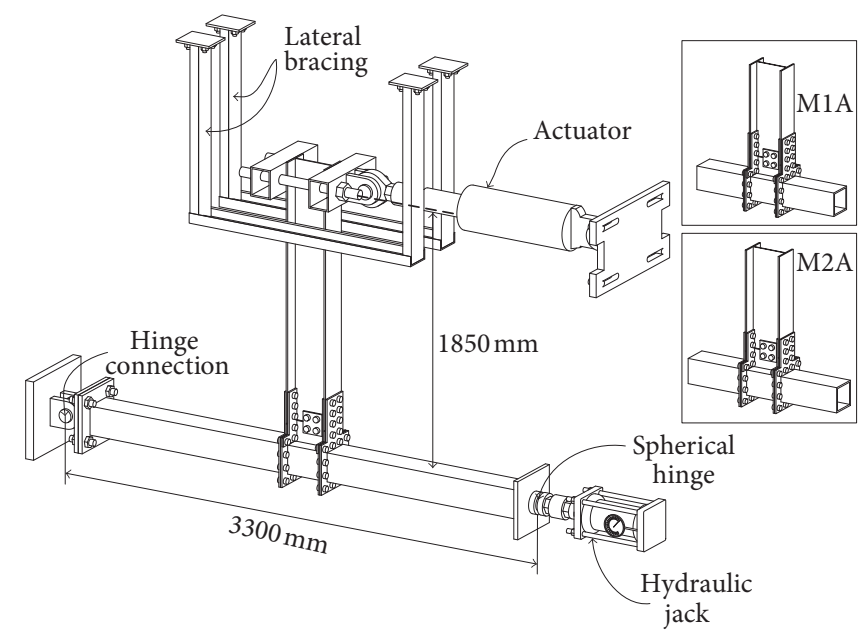

(a)

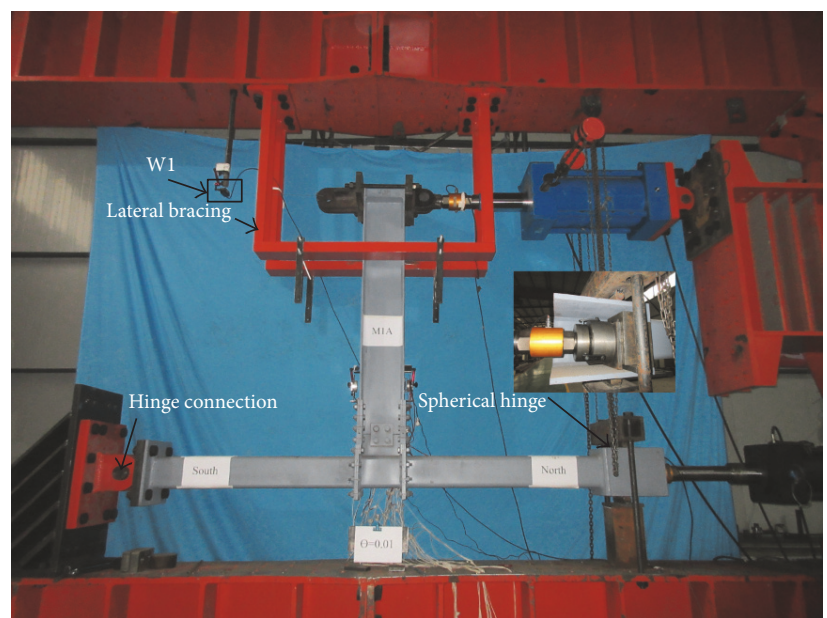

(b)

Figure 4: Test setup. (a) Sketch. (b) Photograph.

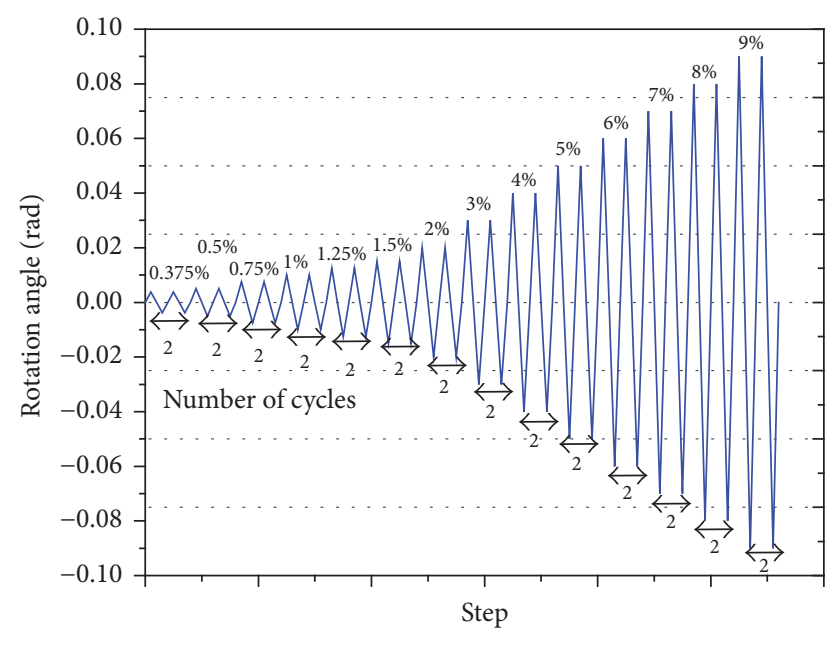

FIGURE 5: Cyclic loading history.

and beam flanges in the joint region. The entire loading process was accompanied by intermittent small sounds, which indicated that the cover plates and the beam flanges were slipping relative to each other for the duration of the loading process. The moment-rotation angle curve of specimen M1A exhibited a sawtooth shape, which shows that the load at the beam end remained nearly constant during the slipping stage. The moment is the load at the beam end multiplied by the length of the beam, which is the moment that the connection was subjected to. The rotation angle is equal to the displacement of the beam end divided by the length of the beam. When the rotation angle reached $0.08 \mathrm{rad}$ cycle, clear scratches caused by the bolts could be observed on the cover plate, and the beam started to twist. The maximum slip distance between the beam flanges and the cover plates reached $18 \mathrm{~mm}$, but the slip distances on the left and right sides of each cover plate were different (Figure $7(\mathrm{~b})$ ). In addition, the left beam flange underwent a large buckling deformation, and the beam web bulged (Figure $7(\mathrm{c})$ ). The curve showed a decrease in the load-bearing capacity, and the bolt holes in the upper row underwent necking deformation. After dissembling the specimen, clear scratches were found on the contact surfaces between the beam flanges and the cover plates; moreover, the edges of the bolt holes in the upper row were found to have been pulled apart, and the bolt holes in the lower two rows were elongated (Figure 7(d)).

A sound was heard when the rotation angle of specimen M1B reached 0.02 rad cycle $(46.5 \mathrm{~mm}$ in the positive direction and $38 \mathrm{~mm}$ in the negative direction). An examination of the joint region showed that slip had occurred between the cover plates and the beam flanges. A sound was also heard when the rotation angle of specimen M1C reached 0.015 rad cycle ( $32 \mathrm{~mm}$ in the positive direction and $27 \mathrm{~mm}$ in the negative direction). Slip was also found to have occurred between the cover plates and the beam flanges.

5.2. Testing Process for Specimen M2. Similar phenomena were observed when applying quasi-static cyclic loads to specimens M2A, M2B, and M2C. Figure 8 shows the failure mode of specimen M2A. A sound was heard when the rotation angle of specimen M2A reached $0.015 \mathrm{rad}$ cycle $(23 \mathrm{~mm}$ in the positive direction and 21 in the negative direction), and slippage occurred between the cover plates and the beam flanges. Moreover, the entire loading process was accompanied by intermittent small sounds, which indicates that the cover plates and the beam flanges were slipping relative to each other for the duration of the loading process. The moment-rotation angle curve of specimen M2A exhibited a sawtooth shape, and the load at the beam end remained approximately constant during the slipping stage. When the rotation angle at the beam end reached $0.09 \mathrm{rad}$ cycle, clear scratches caused by the bolts were observed on the cover plate, but the beam was not twisted. In addition, the maximum slip distance between the beam flanges and the cover plates in the joint region reached $19 \mathrm{~mm}$, and the 


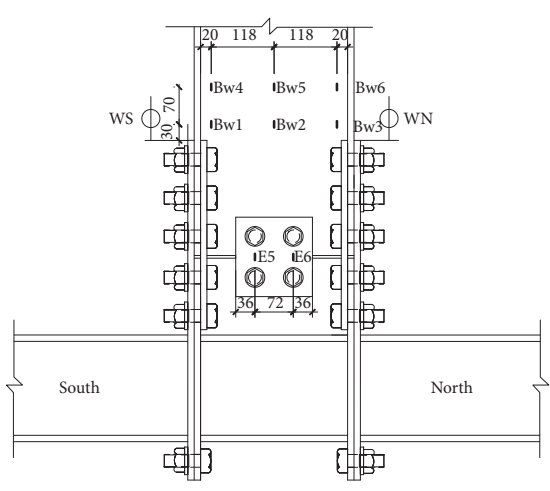

(a)

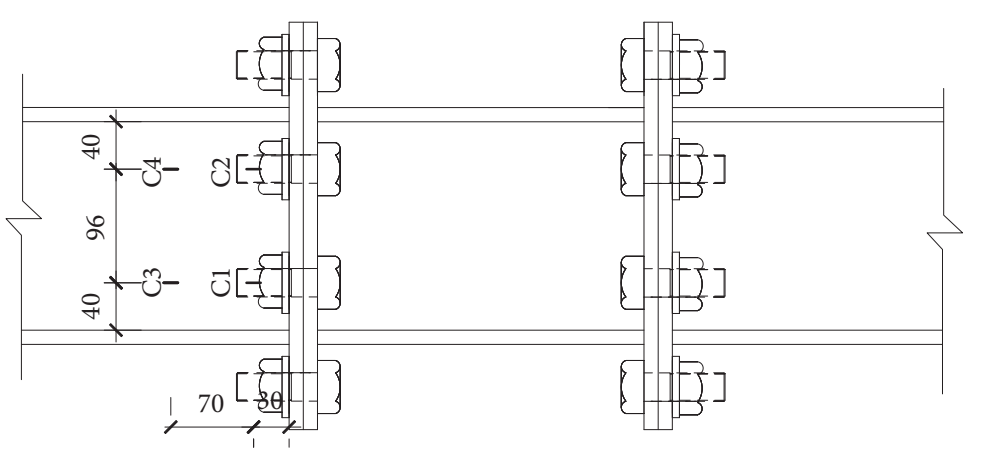

(c)

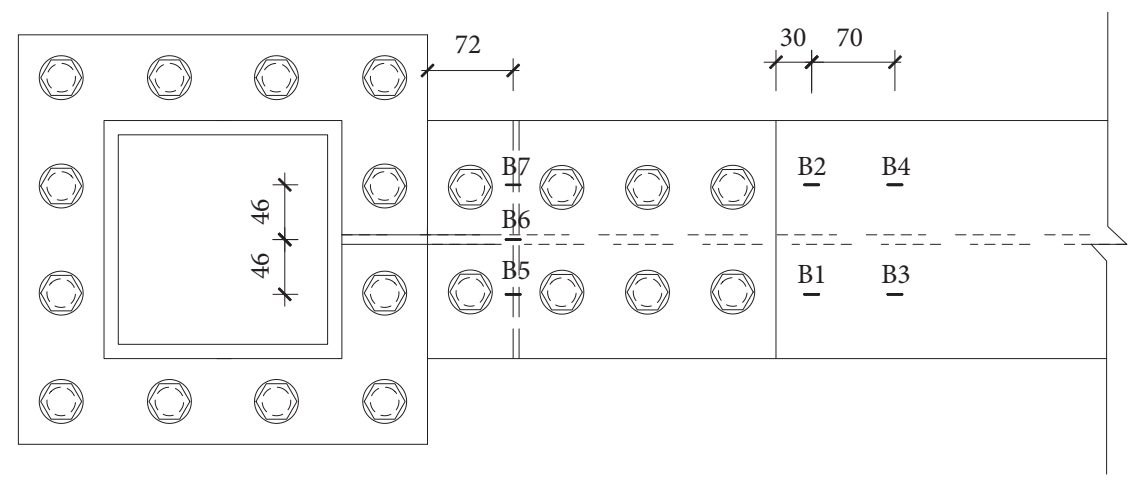

(b)

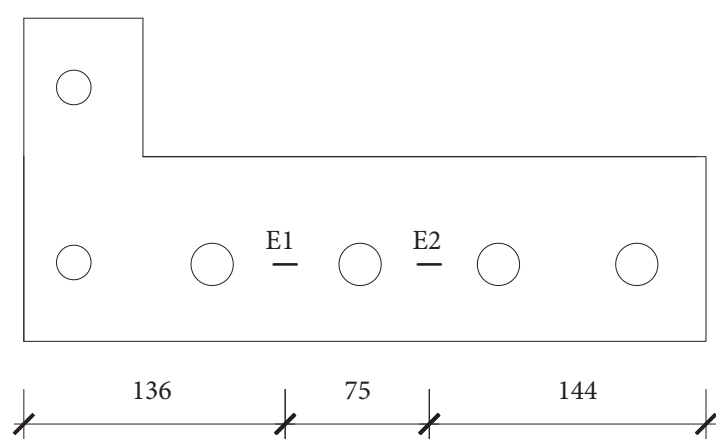

(d)

Figure 6: Arrangements of strain gauges and displacement meters. (a) Front view. (b) Left-side view. (c) Top view. (d) Plate E.

slip distances on the left and right sides of the cover plate were the same (Figure 8(b)). Moreover, the left beam flange underwent a slight buckling deformation, but the web did not bulge. There was a large gap between the beam web and the column base (Figure 8(c)). The curve showed no decrease in the load-bearing capacity. The bolt holes in the upper row were found to have undergone necking deformation. After dissembling the specimen, clear scratches were found on the contact surfaces between the beam flanges and the cover plates; moreover, the edges of the bolt holes were found to have been pulled apart and greatly elongated (Figure 8(d)); the elongated bolt holes of M2 were larger than those of M1.

A sound was heard when the rotation angle at the beam end of specimen M2B reached $0.015 \mathrm{rad}$ cycle $(17.8 \mathrm{~mm}$ in the positive direction and $18 \mathrm{~mm}$ in the negative direction). By examining the joint region, slip was found to have occurred between the cover plates and the beam flanges. A sound was also heard when the rotation angle at the beam end of specimen $\mathrm{M} 2 \mathrm{C}$ reached $0.015 \mathrm{rad}$ cycle $(25 \mathrm{~mm}$ in the positive direction and $25 \mathrm{~mm}$ in the negative direction). Slip was found to have occurred between the cover plates and the beam flanges. The sound occurred because of the slip between the steel parts and could be eliminated by adding a thin copper sheet between them, so that a stable slipping energy dissipation could be obtained [43].

\section{Test Results and Analysis}

6.1. Moment-Rotation Angle Hysteretic Curves. Figure 9 shows the moment-rotation angle hysteretic curves of the six specimens. The moment is the load at the beam end multiplied by the length of the beam, which is the moment that the connection is subjected to. The rotation angle is equal to the displacement of the beam end divided by the length of beam. Specimens M1A, M1B, M1C, M2A, and M2B were loaded until a rotation angle of $0.09 \mathrm{rad}$ was reached, and specimen $\mathrm{M} 2 \mathrm{C}$ was loaded until a rotation angle of $0.07 \mathrm{rad}$ was reached. The curves obtained from the FEA closely match those of the tests, and their maximum bearing capacity in each cycle is almost the same. Based on Figure 9, all of the specimens exhibited a relatively good energy dissipation capacity, ductility, and load-bearing capacity. Due to the relative slip that occurred in the joint region, the hysteretic curves of all of the specimens exhibited a Z-shape, which indicates that the pinching of the hysteretic curves was a result of slip and the bearing capacity could still increase after the slip. The fewer bolts there were, the smaller the slipload was, and the more significantly the hysteretic curve was pinched. Each hysteretic loop had an approximately horizontal slipping segment. The slip-load continuously decreased as the number of loading cycles increased. This was mainly due to two reasons: the pretension of the bolts decreased because the plates were plastically compressed by the bolt gaskets during the loading process, and the slip coefficient of the friction surfaces decreased as the number of loading cycles increased due to wear and tear. When the slip stopped, the bolt shanks came in contact with the bolt holes, and the bolt holes started to bear the load and undergo deformation; in addition, the beam started to dissipate energy through plastic 


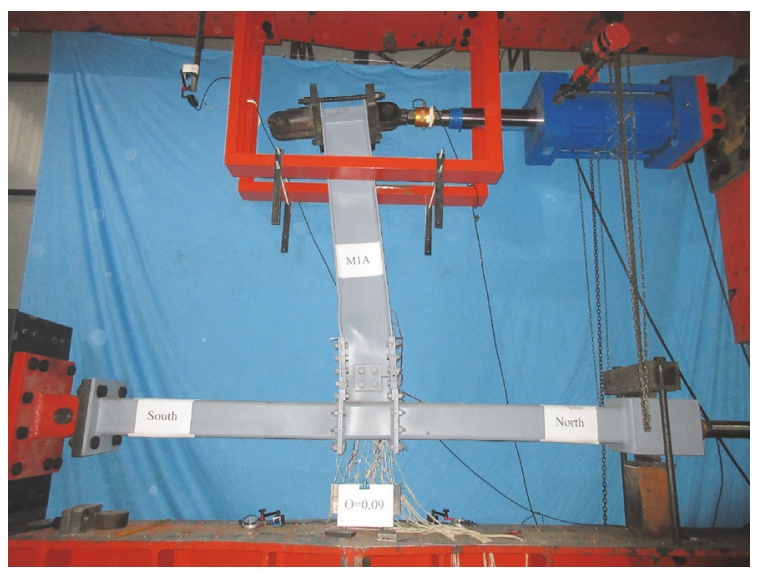

(a)

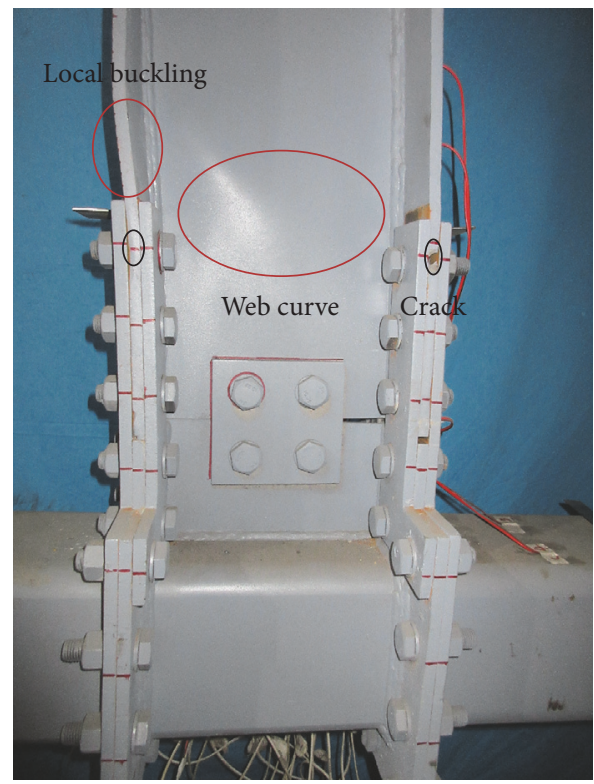

(c)

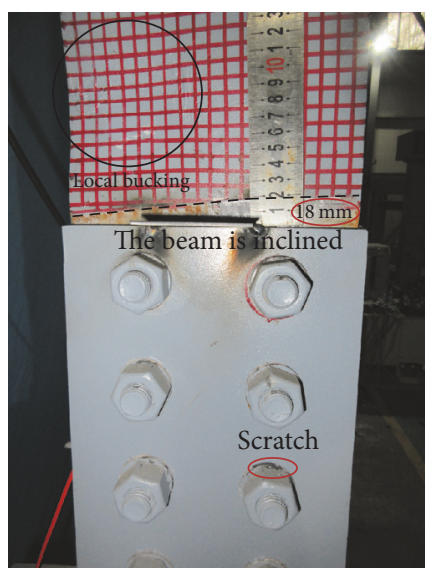

(b)

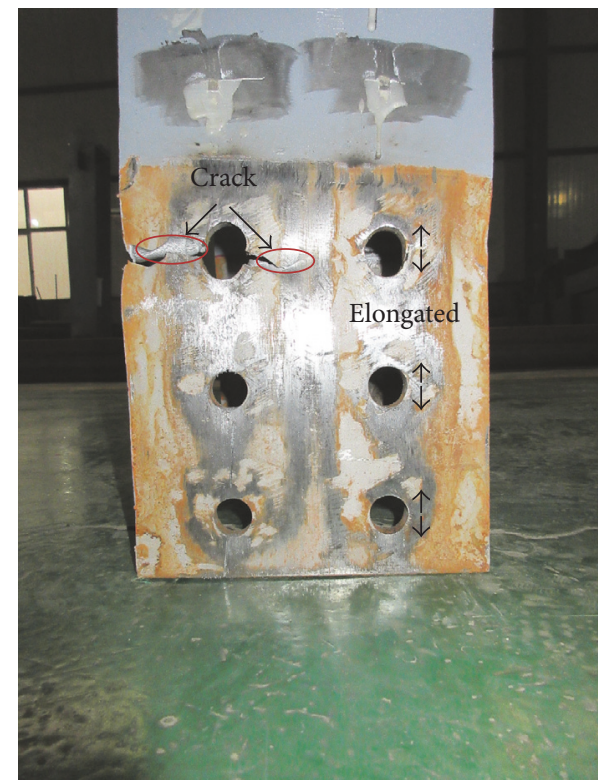

(d)

FIGURE 7: Failure modes of specimen M1A.

deformation. Although this character makes the hysteretic curve look like it is not very wide, it could make the structure avoid collapse because the bearing capacity does not decrease after the slipping dissipation. A comparison shows that the M1 specimens had wider hysteretic curves than the M2 specimens. This is because the M1 specimens had more bolts; thus, their joint regions were stronger, and more energy was dissipated through buckling at the beam end after the bolts slipped. This theory is corroborated by a photograph that shows the deformation of the beam after loading. The size of the bolt holes and the material of the plates E had no significant impact on the connection performance. All of the M1 specimens ultimately failed due to the occurrence of significant buckling at the beam end; that is, their failures were ductile. For the M2 specimens, the beam was not considerably buckled when the load was removed. After dissembling each specimen, the bolt holes were found to have been greatly elongated, and clear cracks had formed near the bolt holes. The moment-rotation angle hysteretic test curves of all of the M1 specimens have decreasing segments after the maximum moment, whereas those of the M2 specimens did not demonstrate such. This is consistent with the phenomena observed during the tests; a plastic hinge formed at the beam end of each M1 specimen, whereas such did not occur in the M2 specimens.

6.2. Performance Indicators. Several performance indicators were obtained by processing the test data, including the moment at which significant slip occurred $\left(M_{s}\right)$, the corresponding rotation angle of the connection $\left(\theta_{s}\right)$, the peak moment at which the load at the beam end reached its maximum $\left(M_{u}\right)$, the ultimate rotation angle at which the displacement reached its maximum $\left(\theta_{u}\right)$, the displacement ductility factor $\left(\mu=\theta_{u} / \theta_{s}\right)$, the plastic rotation angle $\left(\theta_{p}=\right.$ $\left.\theta_{u}-\theta_{s}\right)$, and the total energy dissipated by the specimen $E_{\text {total }}$. 


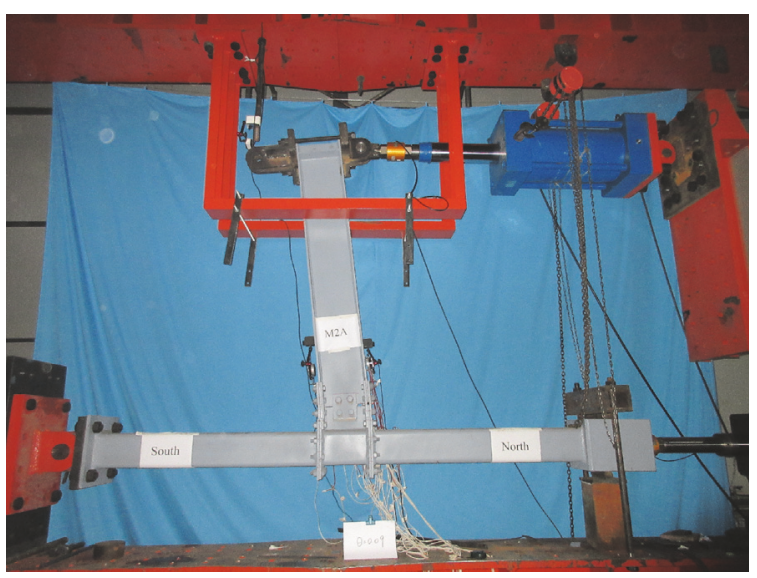

(a)

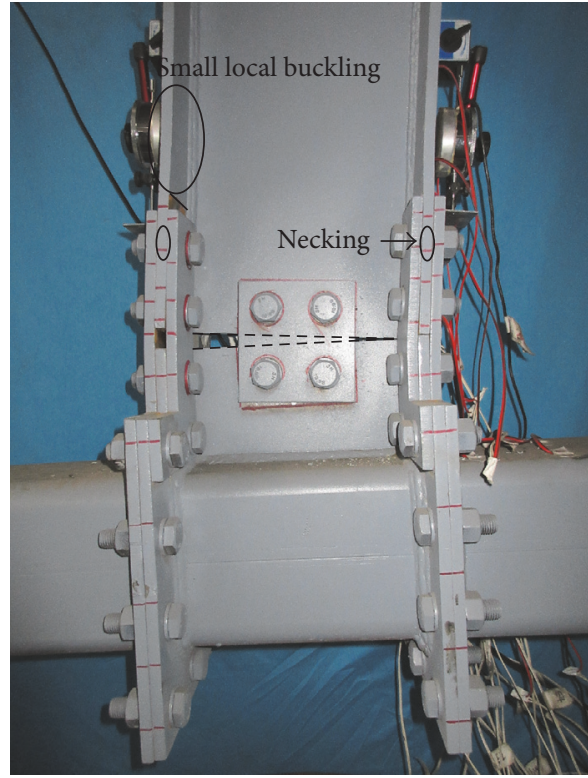

(c)

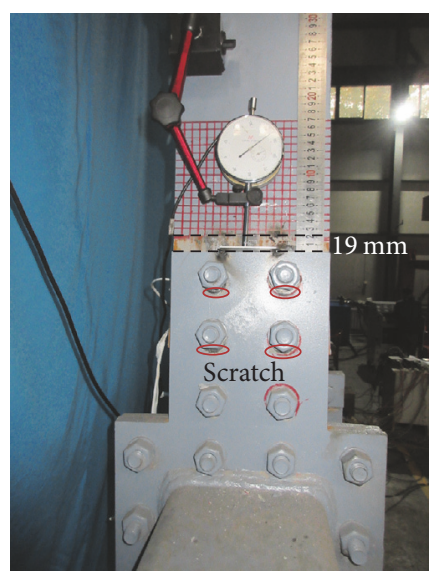

(b)

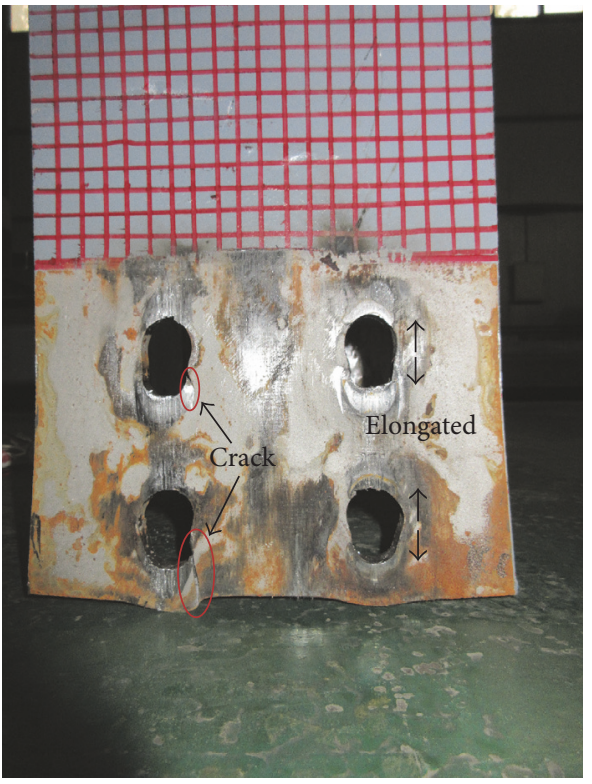

(d)

FIGURE 8: Failure modes of specimen M2A.

Table 3 lists the performance indicators of the six specimens obtained from quasi-static loading tests. The results show that significant slip occurred in the M1 specimens when the rotation angle reached approximately $0.02 \mathrm{rad}$ and in the M2 specimens when the rotation angle reached approximately $0.015 \mathrm{rad}$. The slip moment $M_{s}$ when significant slip occurred in specimens M1 and M2 was approximately $300 \mathrm{kN} \cdot \mathrm{m}$ and $200 \mathrm{kN} \cdot \mathrm{m}$, respectively. This suggests that the more bolts there are on the cover plate, the greater the slip moment is. The rotation angle is small when the slip occurred, which indicates that the connection can dissipate energy through slip during a moderate earthquake and the slip moment can be controlled by varying the number of bolts on the cover plate.

The ultimate moment $M_{u}$ of the M1 specimens reached approximately $400 \mathrm{kN} \cdot \mathrm{m}$, whereas that of the M2 specimens reached approximately $350 \mathrm{kN} \cdot \mathrm{m}$. This indicates that for the specimens that contained more bolts, the frictional contact surface has a larger friction-resistance, and the bolt shank and bolt hole surface bear larger pressures after the conclusion of the slip when the rotation angle was very large, which resulted in a higher load-bearing capacity. Moreover, the connection dissipated more seismic energy through plastic deformation at the beam end. The $\mu$ values of the specimens were symmetrical in the positive and negative directions. The M1 specimens had $\mu$ values of approximately 5 , whereas the M2 specimens had $\mu$ values of approximately 6 . The $\mu$ values of the M1 specimens were smaller than those of the M2 specimens. The rotation angle of the M2 specimens when the slip occurred was smaller than that of the M1 specimens because they contained fewer bolts, leading to a relatively large $\mu$ value but a relatively low energy dissipation capacity. As shown in Table 3, $\mu$ is larger than 4.0 [44] and $\theta_{p}$ is larger than 0.04 [42], and thus the connection specimens had relatively good ductility. 

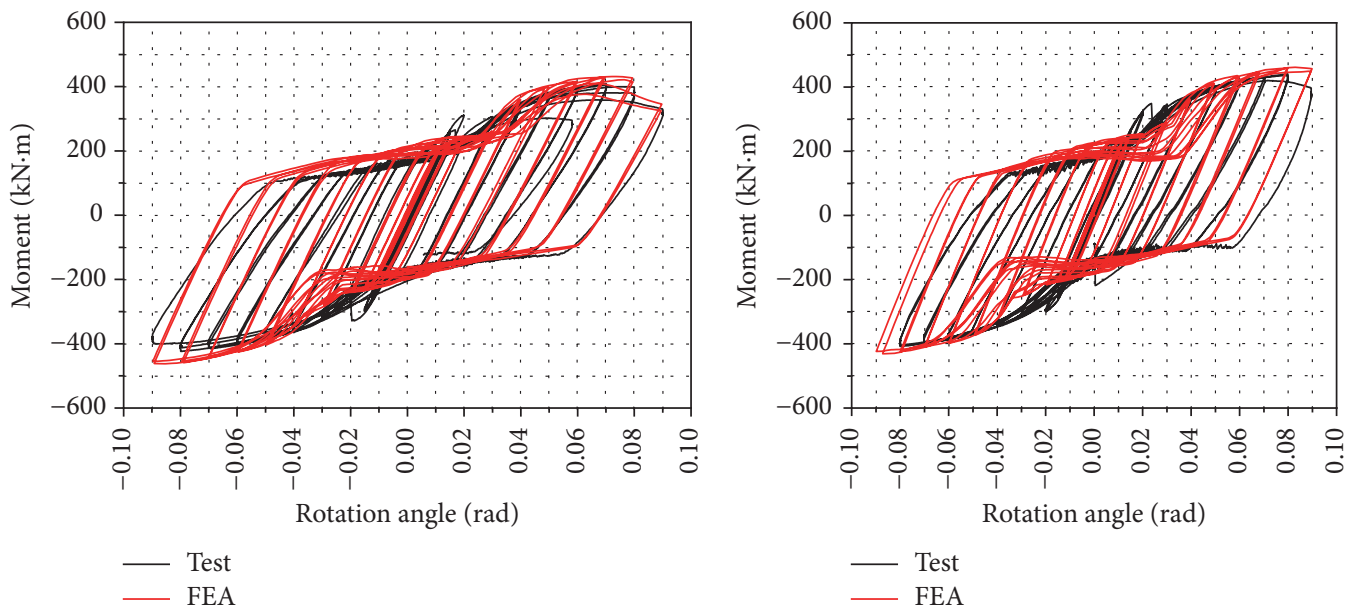

(a)

(b)
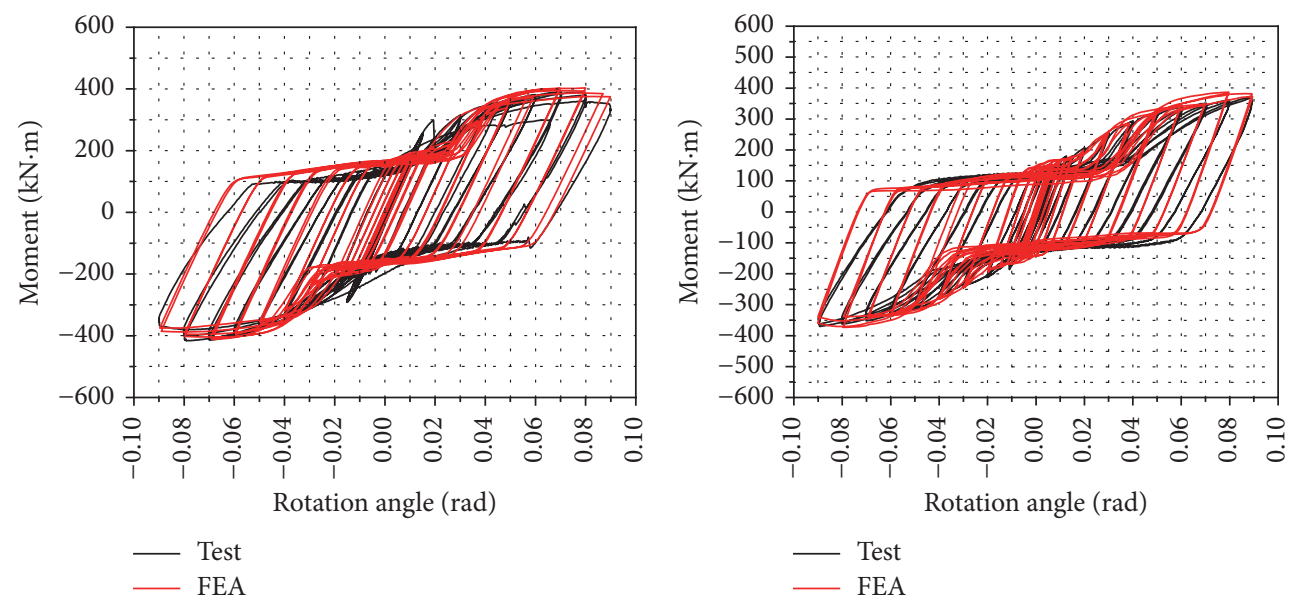

Test

(c)

(d)
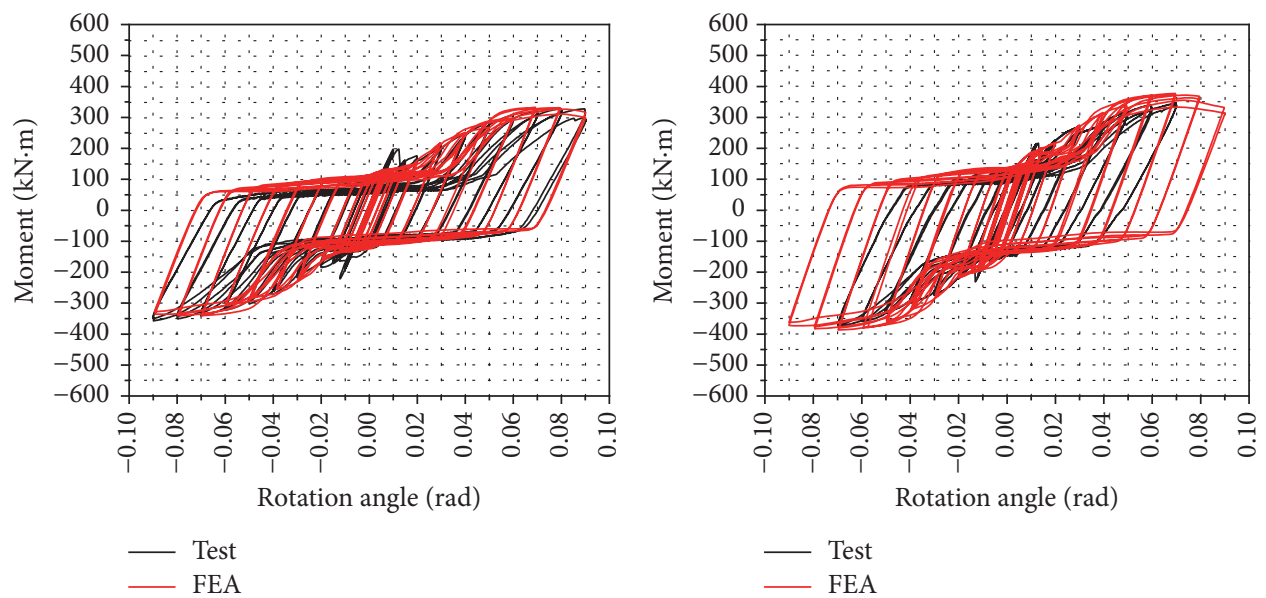

(e)

(f)

FIGURE 9: Moment-rotation angle hysteretic curves. (a) Specimen M1A. (b) Specimen M1B. (c) Specimen M1C. (d) Specimen M2A. (e) Specimen M2B. (f) Specimen M2C.

Compared to the slip moment, the ultimate strength was greatly improved. This indicates that the bolted connections between the cover plates and the flanges are transformed from friction-type to bearing-type as the connection dissipates energy, and the load-bearing capacity increases after the slip is finished. This process is accompanied by continuous increases in the load-bearing capacity and ductility of the connection. The data shown in Table 3 demonstrate that the 
TABLE 3: Primary performance indicators during the quasi-static tests.

\begin{tabular}{|c|c|c|c|c|c|c|c|c|}
\hline Specimen & Loading direction & $M_{s}(\mathrm{kN} \cdot \mathrm{m})$ & $\theta_{s}(\% \mathrm{rad})$ & $M_{u}(\mathrm{kN} \cdot \mathrm{m})(\% \mathrm{rad})$ & $\theta_{u}(\% \mathrm{rad})$ & $\mu$ & $\theta_{p}(\% \mathrm{rad})$ & $E_{\text {total }}$ \\
\hline \multirow{2}{*}{ M1A } & Positive & 310.7 & 1.98 & $408.4(7)$ & 9 & 4.5 & 7.02 & \multirow{2}{*}{$391.3 \mathrm{~kJ}$} \\
\hline & Negative & 298.4 & 1.51 & $412.1(7)$ & 8.99 & 6 & 7.48 & \\
\hline \multirow{2}{*}{ M1B } & Positive & 318.4 & 2 & $431.1(8)$ & 8.95 & 4.5 & 6.95 & \multirow{2}{*}{$374.8 \mathrm{~kJ}$} \\
\hline & Negative & 300.1 & 2 & $402.9(8)$ & 8.01 & 4 & 6.01 & \\
\hline \multirow{2}{*}{ M1C } & Positive & 252.3 & 1.5 & $388.1(7)$ & 8.99 & 6 & 7.49 & \multirow{2}{*}{$353.3 \mathrm{~kJ}$} \\
\hline & Negative & 290.1 & 1.5 & $404.8(7)$ & 9 & 6 & 7.50 & \\
\hline \multirow{2}{*}{$\mathrm{M} 2 \mathrm{~A}$} & Positive & 179.5 & 1.53 & $362.5(8)$ & 8.9 & 5.8 & 7.37 & \multirow{2}{*}{$388 \mathrm{~kJ}$} \\
\hline & Negative & 185.8 & 1.52 & $357.9(8)$ & 8.95 & 5.9 & 7.43 & \\
\hline \multirow{2}{*}{ M2B } & Positive & 160.4 & 1.49 & $325.7(8)$ & 8.99 & 6 & 7.5 & \multirow{2}{*}{$292 \mathrm{~kJ}$} \\
\hline & Negative & 171.2 & 1.51 & $348(8)$ & 8.99 & 6 & 7.48 & \\
\hline \multirow{2}{*}{$\mathrm{M} 2 \mathrm{C}$} & Positive & 179.1 & 1.51 & $342(7)$ & 6.96 & 4.6 & 5.45 & \multirow{2}{*}{$222.1 \mathrm{~kJ}$} \\
\hline & Negative & 179.1 & 1.5 & $366.1(7)$ & 6.99 & 4.7 & 5.49 & \\
\hline
\end{tabular}

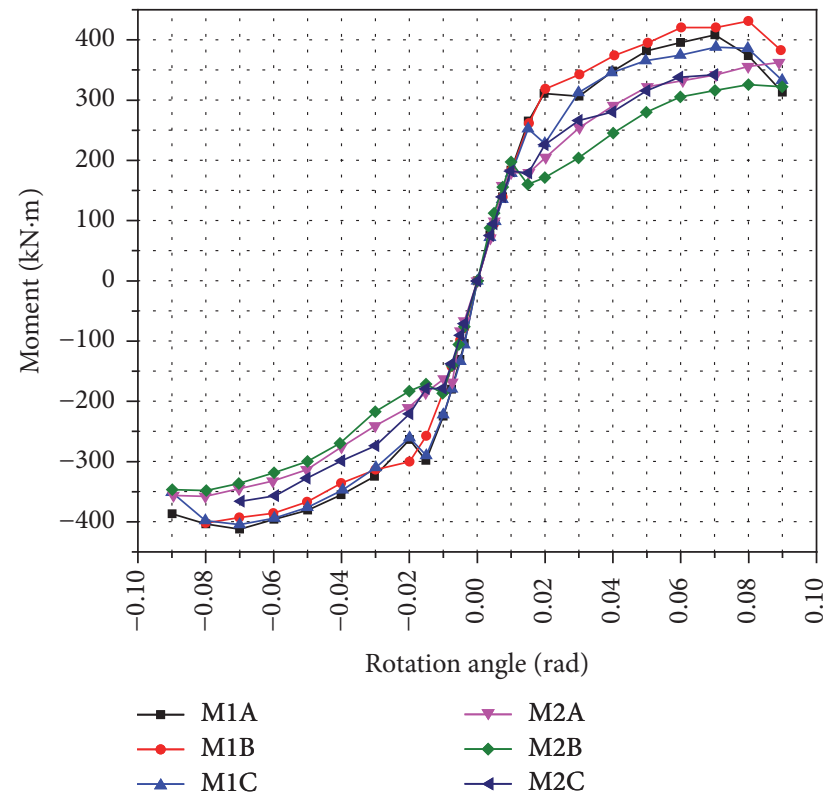

FIGURE 10: Skeleton curves of the specimens.

connection that dissipates energy through slipping has excellent seismic performance and a high load-bearing capacity after the slip is finished.

6.3. Skeleton Curves. The points of the maximum values of the loads in each cycle of the hysteresis curve are extracted and connected in turn to obtain the skeleton curve. Figure 10 shows a comparison of the moment-rotation angle skeleton curves for the six specimens. The three M1 specimens had similar skeleton curves. For these three specimens, slip occurred when the rotation angle reached $0.02 \mathrm{rad}$, which corresponds to a sudden decrease in the skeleton curves of the connection. Afterwards, the bolt shanks came in contact with the bolt hole walls, and the bolt hole walls started to bear the load and undergo deformation, which resulted in an increase in the load-bearing capacity of the connection. Subsequently, the beam end started to buckle in several local areas, which corresponds to the descending segment of the moment-rotation angle skeleton curve. The M1 specimens reached their peak load-bearing capacity of approximately $400 \mathrm{kN} \cdot \mathrm{m}$ when the rotation angle of the beam reached $0.08 \mathrm{rad}$. The three M2 specimens also had similar skeleton curves. In these three specimens, slip occurred when the rotation angle reached $0.015 \mathrm{rad}$, which corresponds to a sudden decrease in the skeleton curves of the connection. Afterwards, the bolt shanks came in contact with the bolt hole walls, and the bolt hole walls started to bear the load and deform, which resulted in an increase in the load-bearing capacity of the connection. However, the beam did not undergo significant local buckling deformation at its end before the load was removed. The M2 specimens reached their peak load-bearing capacity of approximately $350 \mathrm{kN} \cdot \mathrm{m}$ when the rotation angle of the beam reached $0.09 \mathrm{rad}$. Table 3 lists the ultimate load-bearing capacities and other performance indicators in detail. Figure 10 shows that the positive and negative directions of the skeleton curves of the specimens were approximately symmetrical. The skeleton test curves of all of the M1 specimens have decreasing segments after the maximum moment, whereas those of the M2 specimens did not have such. This is consistent with the phenomena observed during the tests, in which a plastic hinge formed at the beam end of each M1 specimen, whereas no plastic hinge formed at the beam end of each M2 specimen.

6.4. Stiffness Degradation. On the basis of the skeleton curves, the stiffness of each point is calculated, the ratio of the stiffness of each point to the initial stiffness is calculated, and the point with the ratio of each point as the vertical coordinate and the rotation angle as the horizontal coordinate is obtained. Drawing a line between these points, the equivalent stiffness degradation coefficient curve is obtained, which shows the law of the stiffness degradation of the connection. Figure 11 shows a comparison of the equivalent stiffness degradation coefficient curves for the six specimens. The curve of each specimen had similar trends in the positive and negative directions. The curves contained three segments in each direction, including a horizontal linear segment, a 


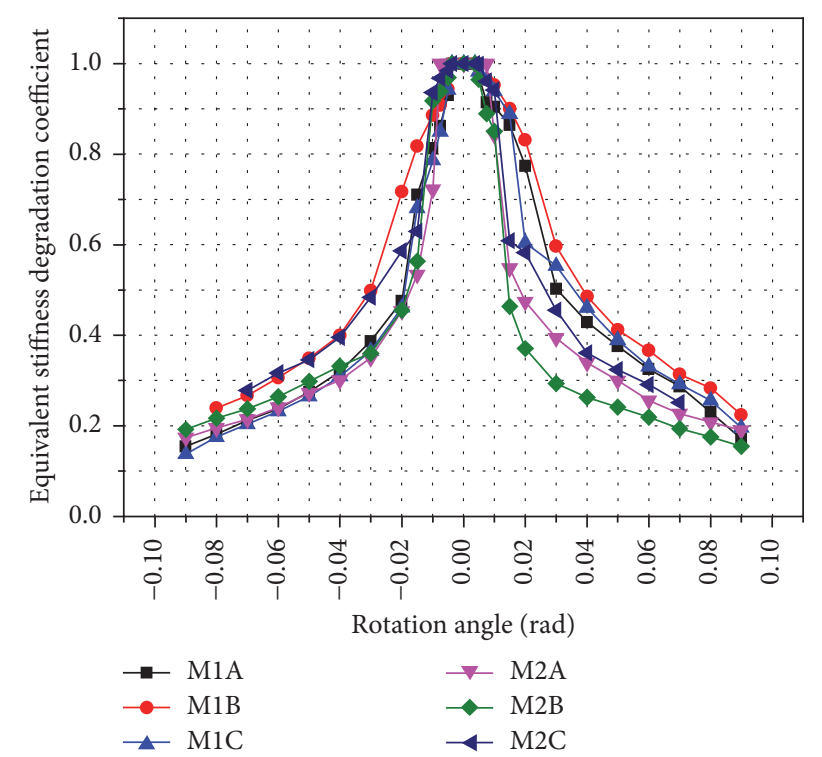

FIGURE 11: Equivalent stiffness degradation coefficient curves of the specimens.

linearly descending segment, and a curved descending segment. Each specimen was in an elastic state during the initial loading stage, and the segment of its curve that corresponds to the initial loading stage was a horizontal straight line. After significant slip occurred, the stiffness of each specimen started degrading at a higher rate, and the corresponding segment of its curve exhibited a sudden linear descent. When the bolts contacted with the bolt hole walls, the slip stopped, at which time the connection was strengthened, and the stiffness degradation slowed down significantly. During the entire loading process, the equivalent stiffness degradation coefficients of the M1 specimens were significantly higher than those of the M2 specimens, which indicates that the stiffness of the specimens that contained fewer bolts degraded at a higher rate.

6.5. Energy Dissipation Capacity. Figure 12 shows the amounts of energy that were dissipated by the six specimens with respect to each rotation angle of connection. The amounts of energy dissipated by the M1 and M2 specimens began to increase significantly in the seventh loading cycle $( \pm 2 \% \mathrm{rad})$ and the sixth loading cycle $( \pm 1.5 \% \mathrm{rad})$, respectively. This indicates that specimens $\mathrm{M} 2 \mathrm{~A}, \mathrm{M} 2 \mathrm{~B}$, and $\mathrm{M} 2 \mathrm{C}$ were no longer in an elastic state and started to slip and strengthen starting in the sixth loading cycle. In specimens $\mathrm{M} 1 \mathrm{~A}, \mathrm{M} 1 \mathrm{~B}$, and $\mathrm{M} 1 \mathrm{C}$, this occurred in the seventh loading cycle. The number of bolts had a significant impact on the slip-load of the connection. The specimens that contained fewer bolts (i.e., the M2 specimens) started to slip sooner than those that contained more bolts (i.e., the M1 specimens). After slip occurred, the beam of each specimen underwent plastic deformation, and energy was dissipated through plastic deformation in addition to slipping, which resulted in a rapid increase in the amount of energy dissipated. The total amounts of energy dissipated by specimens M1A, M1B, M1C, M2A, M2B, and M2C were $391.3 \mathrm{~kJ}(0.08 \mathrm{rad}), 374.8 \mathrm{~kJ}(0.08 \mathrm{rad}), 353.3 \mathrm{~kJ}(0.08 \mathrm{rad})$, $388 \mathrm{~kJ}(0.09 \mathrm{rad}), 292 \mathrm{~kJ}(0.09 \mathrm{rad})$, and $222.1 \mathrm{~kJ}(0.07 \mathrm{rad})$, respectively. Figure 12(a) shows that the energy dissipation capacity of the M1 specimens was significantly higher than that of the M2 specimens when the connection reached the same rotation angle, which indicates that the more bolts there were, the higher the capacity of the connection to dissipate energy was, and the effects of the bolt hole size and the grade of the splint material on the total energy dissipation were small on the basis of the analysis of Figures 9 and 12 .

In this study, the equivalent viscous damping coefficient $h_{e}$ in each hysteretic loop is used to describe the energy dissipation [45]. Figure 12(b) shows that the equivalent viscous damping coefficient of the M1 specimens increased with the increasing rotation angle. This indicates that each specimen of M1 dissipated energy only through slip during the initial stage and thus had a relatively low energy dissipation capacity. Later, the energy dissipation capacity of the specimen increased due to the compressive deformation of the bolts' hole walls and the plastic deformation at the beam end. Because there were fewer bolts at the beam end of the M2 specimens than in the M1 specimens, the M2 specimens slip at smaller rotation angles, and their equivalent viscous damping coefficients were larger than those of M1 at the early stage. But, with the process of slipping, the friction of M2 dropped significantly because the bolt tension drops drastically. Thus, the energy dissipation dropped, as did the equivalent viscous damping coefficient. With the development of plastic deformation on the bolt hole and beam end, the energy dissipation increases again, and then the equivalent viscous damping coefficient increases, too. Figure 12 shows that the connection dissipates energy by different modes at different stages. There are three stages. During the first stage, the connection dissipates energy mainly through slip. During the second stage, the connection dissipates energy mainly through slip and the compressive deformation of the bolt hole walls. During the third stage, the connection dissipates energy mainly through slip and plastic deformation at the beam end. The energy dissipation capacity of the M1 specimens is higher than that of the M2 specimens because the bolt constraints (friction and bearing pressure) of the M1 specimens are stronger and the beam end undergoes more plastic deformation. Except for M2B, when the rotation angle is greater than 0.06 , the equivalent viscous damping coefficients of the connections are greater than 0.2 . This shows that the connections have a high energy dissipation capacity, except M2B.

6.6. Strain Analysis. Figure 13 shows the strain-rotation angle curves for the six specimens with respect to four locations: the beam flanges in the joint region, the beam web in the joint region, the cover plates in the joint region, and plate $\mathrm{E}$. The two black horizontal lines represent the yield strain of Q235 steel $\left(\varepsilon_{y}= \pm 1.383 \times 10^{-3}\right)$, and the two red horizontal lines represent the yield strain of Q345 steel $\left(\varepsilon_{y}= \pm 1.785 \times\right.$ $\left.10^{-3}\right)$. The specimens remained elastic in these four locations before reaching the yield strain. In the M1 specimens, the 


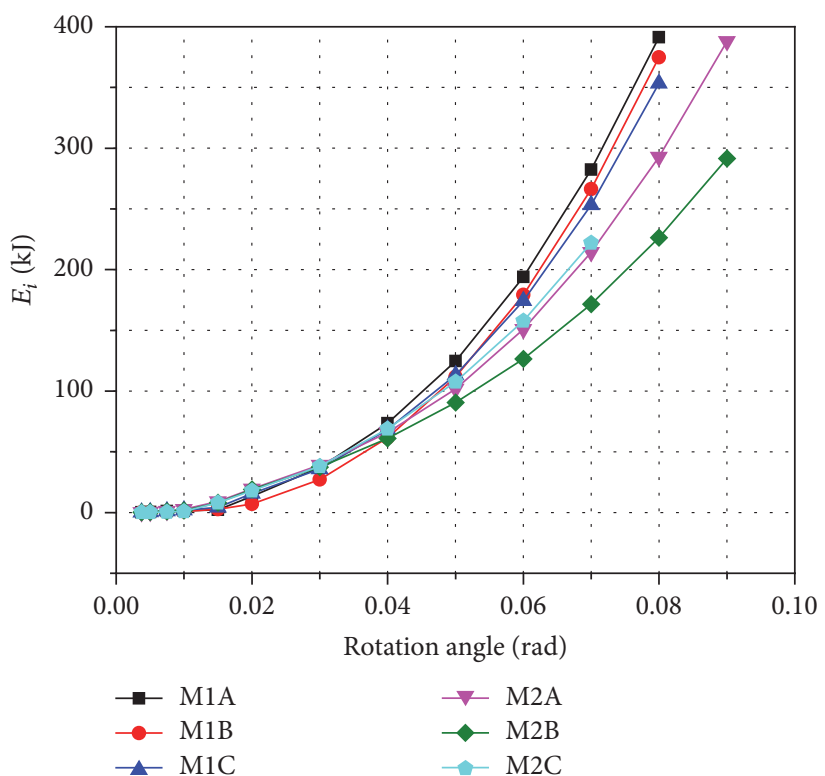

(a)

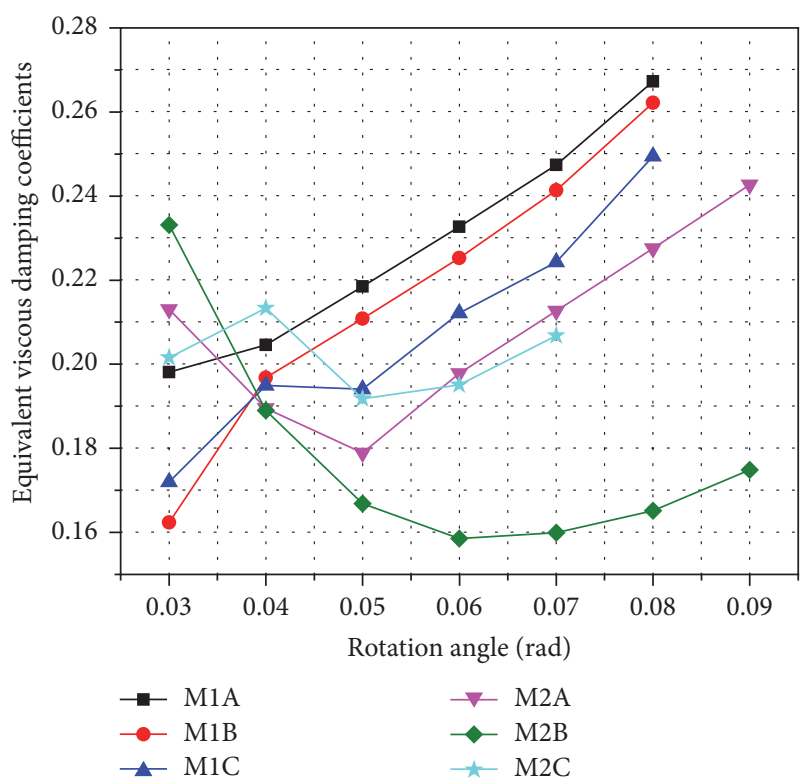

(b)

FIGURE 12: Energy dissipation capacity for each rotation angle. (a) Energy dissipation capacity curves of the specimens. (b) Equivalent viscous damping coefficient curves of the specimens.

beam flanges in the joint region yielded first, followed by the cover plates in the joint region, the splints, and the beam web in the joint region. In the M2 specimens, the cover plates in the joint region yielded first, followed by the beam flanges in the joint region, the splints, and the beam web in the joint region.

\section{Finite Element Analysis}

7.1. Basic Information of the FE Model. Numerical simulations were performed using the finite element analysis software ABAQUS. The six connections were subjected to quasistatic FEA. The FE models were established using the same dimensions as those of the test specimens. The steel beam, steel columns, and high-strength bolts were all simulated using 3D solid elements (C3D8R). In addition, the mesh was refined in the areas where the stress is relatively large based on the results of the tests and the theoretical analysis. The friction coefficient used in the modeling was obtained from the antislip tests. To determine the constitutive relations of the materials, nominal stress-strain curves were obtained from the tests (shown in Table 2) and converted to true stress-strain curves for the FEA. The kinematic hardening of the materials is used for the seismic finite element analysis. The interactions between the bolts, splint plate, steel beam, and column are all built, including the positive-pressure contact relationships and frictional contact relationships. The lateral surface of the bolt shank has a potential positivepressure contact relationship with the wall of the bolt hole. The friction coefficient between the bolt and steel plates is 0.05 and that between the steel plates is 0.35 . Based on the actual boundary conditions that were used during the tests, the end of each square HSS column was simulated as a hinged end. To be consistent with the tests, lateral braces were simulated to constrain the lateral displacement of the $\mathrm{H}$ section steel beam. A low-frequency cyclic load was applied at the beam end, and the same loading regime that was used in the tests was used in the simulations. Figure 14 shows the FE model of the connection.

7.2. Failure Modes. A comparison of the hysteretic curves in Figure 9 obtained from the tests and the FEA shows good agreement between them. A comparison of the failure modes in Figure 15 obtained from the tests and the FEA similarly shows that the deformation and strain of the FEA agreed well with the test results, which verifies the FE model. Figures 15(a) and 15(b) show the deformation and strain in the joint regions of specimens M1A and M2A, respectively, and Figures $15(\mathrm{c})$ and $15(\mathrm{~d})$ show the deformation and strain in the cover plate regions of specimens M1A and M2A, respectively. The bolt holes on the beam flanges and cover plates experienced a very high strain. Figures 15(e) and 15(f) show the deformation and strain in the beam end of specimens M1A and M2A, respectively, indicating that the bolt holes on the beam end are elongated. The color contours in the FEA results show the strain of the components. The deeper the color in the picture is, the greater the strain is.

The FEA results were thus consistent with the test results. The FEA results for specimen M1A show that after loading, a plastic hinge formed at the beam end in the joint region, the web bulged, and only the bolt holes in the upper row were significantly elongated. The areas under relatively high stress were mainly located near the beam end and on the cover plate. The FEA results for specimen M2A show that a small buckling deformation only occurred in some areas at the beam end, the beam web did not bulge, and all of the bolt holes at the beam 

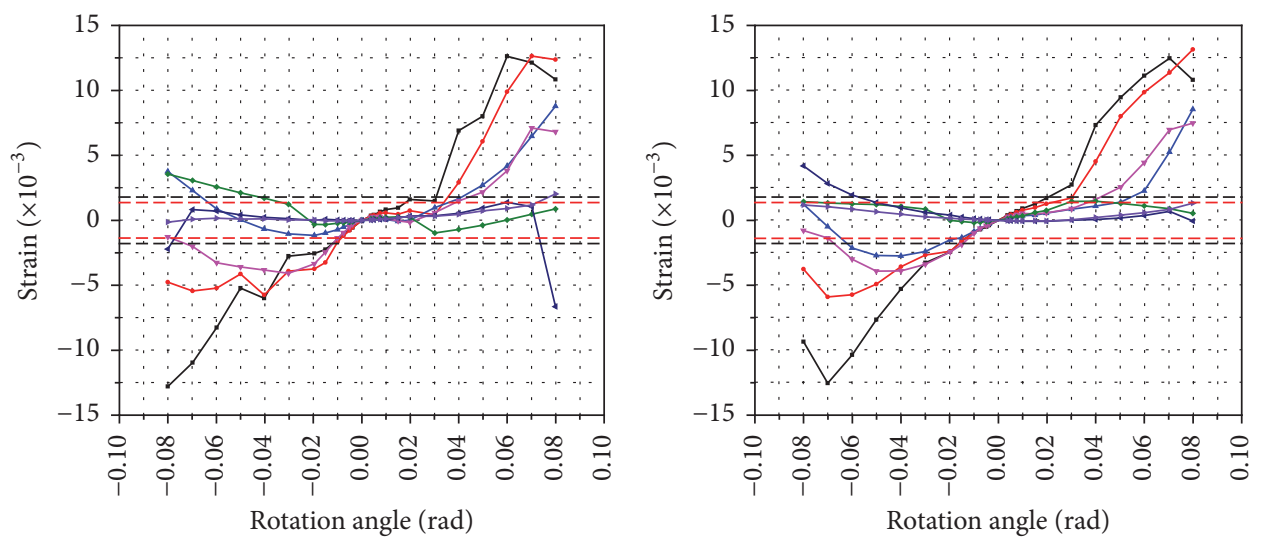

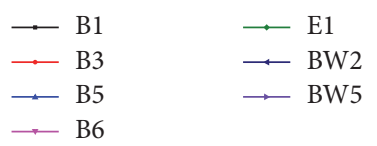

(a)
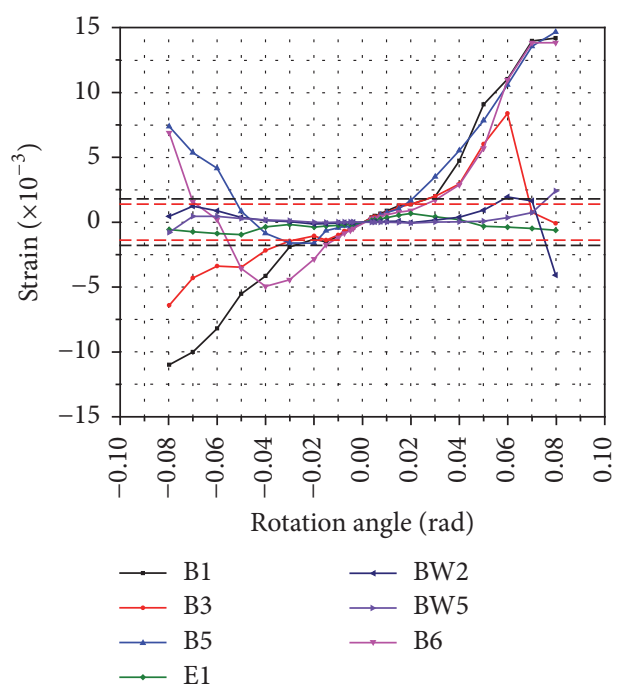

(c)

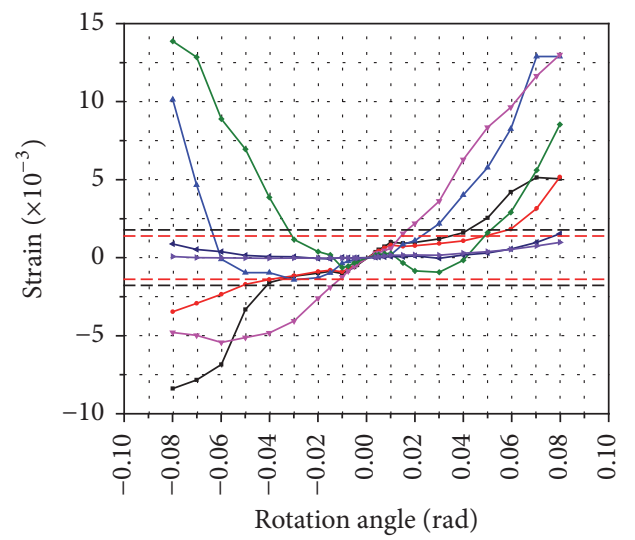

(e)

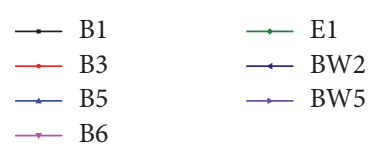

(b)
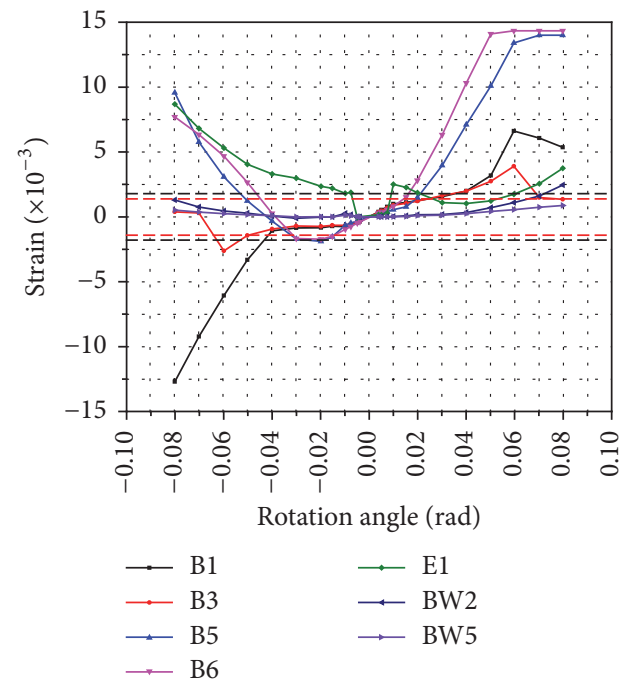

(d)

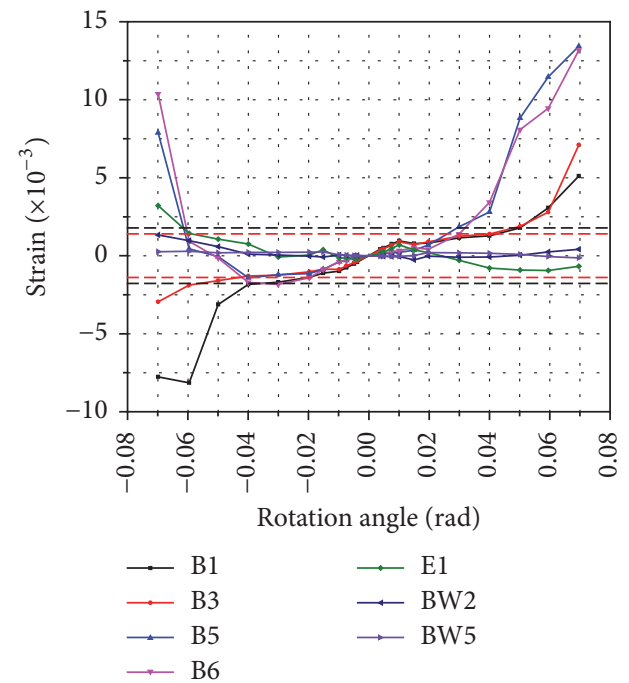

(f)

FIgURE 13: Strain under cyclic loading. (a) Specimen M1A. (b) Specimen M1B. (c) Specimen M1C. (d) Specimen M2A. (e) Specimen M2B. (f) Specimen M2C. 


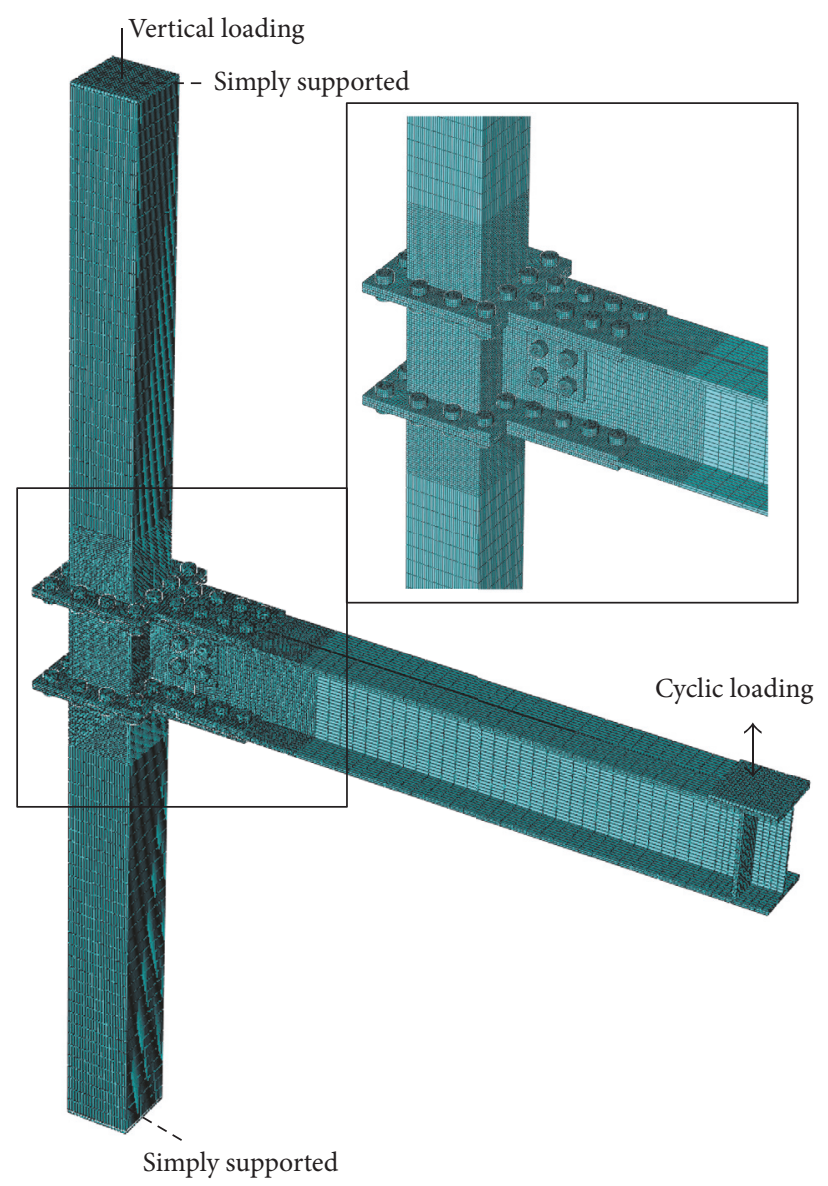

FIGURE 14: Finite element model.

end were greatly elongated. The areas under relatively high stress were located near the bolt holes on the cover plate and the bolt holes at the beam end. A comparison of the stress distributions from the FEA and the strain curves obtained from the tests shows that the areas under relatively high stress in the simulations were the same as those areas where large strains and relatively large deformations occurred in the tests.

\section{Conclusion}

A site-bolted beam-column connection that is suitable for modularized prefabricated steel structures was proposed. Six connection specimens were subjected to quasi-static cyclic loading tests and FEA. The FE model was validated by comparing the results of the FEA and tests. The following conclusions are drawn from this study.

The M1 specimens dissipated energy by the following mechanism. During the initial loading stage, energy was mainly dissipated by slip. After the bolt hole wall started to bear the load, energy was mainly dissipated by slip as well as the plastic deformation of the bolt holes. When the rotation angle was excessively large, the seismic energy was dissipated mainly by slip, the plastic deformation of the bolt holes, and the plastic deformation at the beam end. The M2 specimens dissipated energy by a similar mechanism; however, when the rotation angle was excessively large, seismic energy was still dissipated by slip and the deformation of the bolt holes, and only slight plastic deformation was observed in the joint region. The more bolts there were, the larger the buckling deformation of the flange at the beam end was, and the greater the energy dissipation capacity of the connection was.

The M1 specimens failed under quasi-static cyclic loading due to the relatively large local buckling deformation of the flange at the beam end. The M2 specimens failed under quasi-static cyclic loading due to cross-sectional rupturing at the bolt holes in the innermost row on the flange at the beam end and the slight buckling deformation of the cantilever beam flange near the joint region. The connection specimens underwent sufficient plastic deformation before failure, and the ultimate rotation angle reached 0.09 rad; thus, their failure was ductile. The observations revealed that the fewer bolts there were in the joint region, the earlier the slip occurred. Therefore, the ductility factor of the M2 specimens was greater than that of the M1 specimens. Increasing the number of bolts can effectively increase the slip moment of the connection and cause an outward shift of the plastic hinge.

The strains on the sections at the beam flange near the joint region, at the bolt holes in the innermost row on the cover plate, and at the bolt holes in the outermost row on the beam end were greater than those at other locations. 

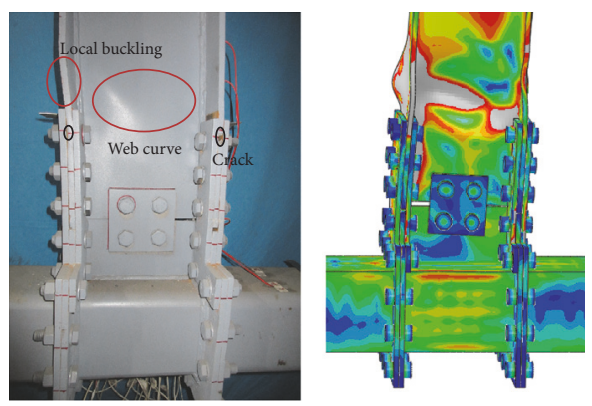

(a)
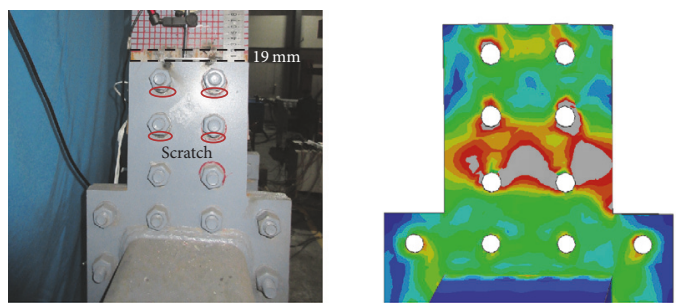

(d)

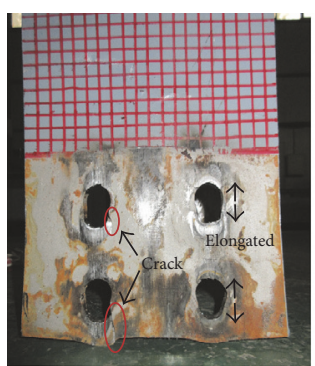

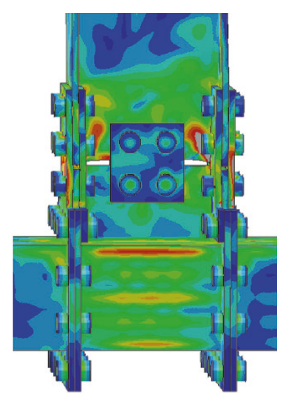

(b)

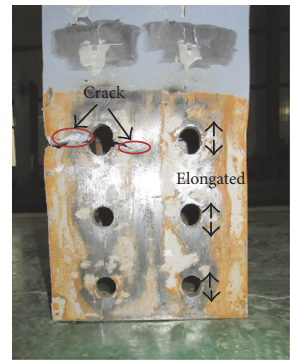

(e)
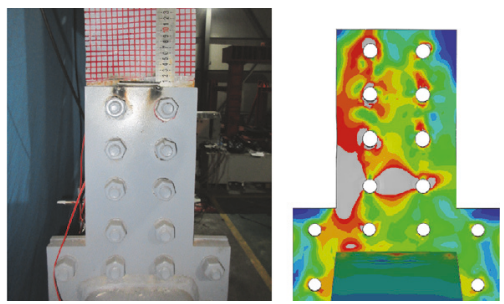

(c)
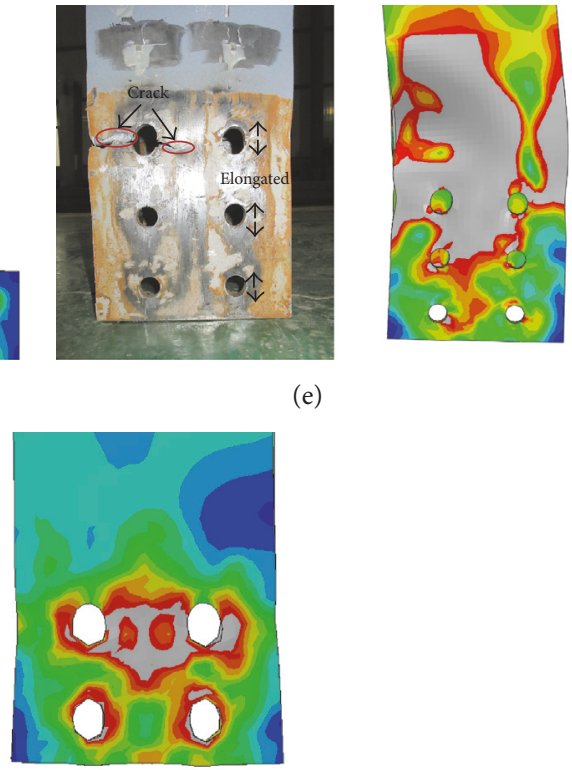

(f)

FIGURE 15: Comparison of the failure modes of the specimens in the experiments and the FEM analyses. (a) Joint region of specimen M1A. (b) Joint region of specimen M2A. (c) Cover plate of specimen M1A. (d) Cover plate of specimen M2A. (e) Beam end of specimen M1A. (f) Beam end of specimen M2A.

These three sections are weak sections and thus require safety checks during the connection design process.

The comparative analysis showed that the number of bolts in the joint region was a major parameter that affected the connection's performance. The more bolts there were in the joint region, the wider the hysteretic curve of the connection was, the greater the deformation of the beam flange near the joint region was, and the greater the energy dissipation capacity of the connection was. The material of the splint plates and the size of the bolt holes at the beam end had no significant impact on the connection's performance. The test and FEA results showed that the proposed connection exhibited reasonable seismic performance (e.g., hysteretic behavior, energy dissipation capacity, ductility, and plastic rotation capacity) while meeting the requirements of easy onsite installation and fast assembly.

\section{Conflicts of Interest}

The authors declare that there are no conflicts of interest regarding the publication of this paper.

\section{Acknowledgments}

The authors gratefully acknowledge the support for this work, which was funded by the National Key Research and Development Program of China (016YFC0701503), the National Natural Science Foundation of China (51678010), the Beijing Municipal Natural Science Foundation (8172009), and the Beijing Municipal Science and Technology Plan Program (Z171100002217017).

\section{References}

[1] D. K. Miller, "Lessons learned from the Northridge earthquake," Engineering Structures, vol. 20, no. 4-6, pp. 249-260, 1998.

[2] M. Nakashima, K. Inoue, and M. Tada, "Classification of damage to steel buildings observed in the 1995 HyogokenNanbu earthquake," Engineering Structures, vol. 20, no. 4-6, pp. 271-281, 1998.

[3] E. P. Popov, T.-S. Yang, and S.-P. Chang, "Design of steel MRF connections before and after 1994 Northridge earthquake," Engineering Structures, vol. 20, no. 12, pp. 1030-1038, 1998. 
[4] S. Naimi, M. Celikag, and A. A. Hedayat, "Ductility enhancement of post-northridge connections by multilongitudinal voids in the beam web," The Scientific World Journal, vol. 2013, Article ID 515936, 2013.

[5] Z. F. Li, Y. J. Shi, H. Chen, and Y. Q. Wang, "Nonlinear element analysis of improved beam-column joint of steel structure," Building Structure, vol. 32, no. 9, pp. 015-018, 2002 (Chinese).

[6] D. W. Zhao, Y. J. Shi, and H. Chen, "Experimental study of beam-column joint under low cycling load," Building Structure, vol. 30, no. 9, pp. 003-007, 2000 (Chinese).

[7] C.-C. Chen, C.-C. Lin, and C.-H. Lin, "Ductile moment connections used in steel column-tree moment-resisting frames," Journal of Constructional Steel Research, vol. 62, no. 8, pp. 793801, 2006.

[8] C.-C. Chen and C.-C. Lin, "Seismic performance of steel beamto-column moment connections with tapered beam flanges," Engineering Structures, vol. 48, pp. 588-601, 2013.

[9] A. Astaneh-Asl, Seismic Design Steel Column-Tree Moment Resisting Frames, Structural Steel Educational Council, Berkeley, Calif, USA, 1997.

[10] J. Ribeiro, A. Santiago, C. Rigueiro, and L. S. Da Silva, "Analytical model for the response of T-stub joint component under impact loading," Journal of Constructional Steel Research, vol. 106, pp. 23-34, 2015.

[11] J. Ribeiro, A. Santiago, C. Rigueiro, P. Barata, and M. Veljkovic, "Numerical assessment of T-stub component subjected to impact loading," Engineering Structures, vol. 106, pp. 450-460, 2016.

[12] J. W. Hu, R. T. Leon, and T. H. Park, "Mechanical modeling of bolted T-stub connections under cyclic loads part I: stiffness modeling," Journal of Constructional Steel Research, vol. 67, no. 11, pp. 1710-1718, 2011.

[13] J. W. Hu, R. T. Leon, and T. Park, "Mechanical models for the analysis of bolted T-stub connections under cyclic loads," Journal of Constructional Steel Research, vol. 78, pp. 45-57, 2012.

[14] A. K. Dessouki, A. H. Youssef, and M. M. Ibrahim, "Behavior of I-beam bolted extended end-plate moment connections," Ain Shams Engineering Journal, vol. 4, no. 4, pp. 685-699, 2013.

[15] G. S. Prinz, A. Nussbaumer, L. Borges, and S. Khadka, "Experimental testing and simulation of bolted beam-column connections having thick extended endplates and multiple bolts per row," Engineering Structures, vol. 59, pp. 434-447, 2014.

[16] Y. Shi, G. Shi, and Y. Wang, "Experimental and theoretical analysis of the moment-rotation behaviour of stiffened extended end-plate connections," Journal of Constructional Steel Research, vol. 63, no. 9, pp. 1279-1293, 2007.

[17] K. D. Tsavdaridis and T. Papadopoulos, "A FE parametric study of RWS beam-to-column bolted connections with cellular beams," Journal of Constructional Steel Research, vol. 116, pp. 92113, 2016.

[18] R. Bai, S.-L. Chan, and J.-P. Hao, "Improved design of extended end-plate connection allowing for prying effects," Journal of Constructional Steel Research, vol. 113, pp. 13-27, 2015.

[19] G.-Q. Li, L.-Z. Chen, J.-T. Li, and G.-B. Lou, "Modeling of endplate bolted composite connection in fire considering axial force effects," Journal of Constructional Steel Research, vol. 76, pp. 133143, 2012.

[20] R. Rahnavard, N. Siahpolo, M. Naghavi, and A. Hassanipour, "Analytical study of common rigid steel connections under the effect of heat," Advances in Civil Engineering, vol. 2014, Article ID 692323, 10 pages, 2014.
[21] C. Fang, M. C. H. Yam, A. C. C. Lam, and L. Xie, "Cyclic performance of extended end-plate connections equipped with shape memory alloy bolts," Journal of Constructional Steel Research, vol. 94, pp. 122-136, 2014.

[22] M. Mirzaie Aliabadi, M. R. Bahaari, and S. Torabian, "Design and analytical evaluation of a new self-centering connection with bolted T-stub devices," Advances in Materials Science and Engineering, vol. 2013, Article ID 163021, 2013.

[23] I. Faridmehr, Y. Ahmad, M. M. Tahir, and M. H. Osman, "Cyclic and explosive evaluation of new proposed steel joint," Advances in Civil Engineering, vol. 2016, Article ID 4975097, 2016.

[24] X. C. Liu, A. X. Xu, A. L. Zhang, Z. Ni, H. X. Wang, and L. Wu, "Static and seismic experiment for welded joints in modularized prefabricated steel structure," Journal of Constructional Steel Research, vol. 112, pp. 183-195, 2015.

[25] X. C. Liu, S. H. Pu, A. L. Zhang et al., "Static and seismic experiment for bolted-welded joint in modularized prefabricated steel structure," Journal of Constructional Steel Research, vol. 115, pp. 417-433, 2015.

[26] X. C. Liu, S. H. Pu, A. X. Xu, Z. Ni, A. L. Zhang, and Z. W. Yang, "Experimental study on static and seismic performance of bolted joint in modularized multi-layer and high-rise prefabricated steel structures," Journal of Building Structures, vol. 36, no. 12, pp. 43-51, 2015 (Chinese).

[27] X. C. Liu, Z. W. Yang, H. X. Wang, A. L. Zhang, S. H. Pu, and L. Wu, "Seismic performance study on beam-to-column joint of bolted assembled multi-high-level steel structure," Journal of Building Structures, vol. 38, no. 3, pp. 43-51, 2017 (Chinese).

[28] X. Liu, Z. Yang, H. Wang et al., "Seismic performance of $\mathrm{H}$-section beam to HSS column connection in prefabricated structures," Journal of Constructional Steel Research, vol. 138, pp. 1-16, 2017.

[29] X. C. Liu, S. H. Pu, and A. L. Zhang, "Performance analysis and design on bolted connections in modularized prefabricated steel structures," Journal of Constructional Steel Research, vol. 19, no. 9, pp. 183-195, 2017.

[30] X. Liu, A. Zhang, J. Ma, Y. Tan, and Y. Bai, "Design and model test of a modularized prefabricated steel frame structure with inclined braces," Advances in Materials Science and Engineering, vol. 2015, Article ID 291481, 12 pages, 2015.

[31] F. X. Hu, G. Shi, Y. J. Shi et al., "Experimental study on seismic performance of specifically pre-fabricated beam-column connections," Journal of Building Structures, vol. 35, no. 7, pp. 034043, 2014 (Chinese).

[32] Q. J. Wang, Y. N. Zhang, C. Y. Xu et al., "Seismic test for fabricated connection of concrete-filled steel tubular column and H-shaped steel beam," Journal of Shenyang University of Technology, vol. 36, no. 3, pp. 355-360, 2014 (Chinese).

[33] Y. S. Yu, L. Wei, and G. X. Fu, "Nonlinear static analysis of a new beam-column assembly rigid connection," World Earthquake Engineering, vol. 30, no. 1, pp. 050-056, 2014 (Chinese).

[34] L. X. Jiang, Y. L. Guo, Q. T. Lu et al., "Behavior of a new type of self-locked joint of concrete-filled steel tubular column and steel beam," Construction Technology, vol. 38, no. 3, pp. 067-069, 2009 (Chinese).

[35] A. Zhang, L. Zhao, X. Liu, and Y. Sun, "Monotonic experimental study of prefabricated square tubular column to truss beam connections," China Civil Engineering Journal, vol. 47, pp. 169174, 2014 (Chinese).

[36] R. L. Ma, Y. Yang, Q. S. Chen et al., "Seismic performance testing study on high strength bolt connections with slotted holes," 
Journal of Building Structures, vol. 30, no. 1, pp. 101-106, 2009 (Chinese).

[37] GB 50011, Code for Seismic Design of Buildings, China Planning Press, Beijing, China, 2010.

[38] JGJ 99, Technical Specification for Steel Structure of Tall Building, China Architecture \& Building Press, Beijing, China, 2015.

[39] M. Gerami, H. Saberi, V. Saberi, and A. S. Daryan, "Cyclic behavior of bolted connections with different arrangement of bolts," Journal of Constructional Steel Research, vol. 67, no. 4, pp. 690-705, 2011.

[40] GB/T 288. 1. Metallic Materials: Tensile Testing at Ambient Temperature, China Standards Press, Beijing, China, [In Chinese] 2010.

[41] GB50205, Code for Acceptance of Construction Quality of Steel Structures, China Planning Press, Beijing, China, 2001.

[42] ANSI/AISC341, Seismic Provisions for Structural Steel Buildings, American Institute of Steel Construction, Chicago, Ill, USA, 2010.

[43] A. L. Zhang, Q. X. Quan, X. X. Zhan, and X. F. Ma, "Force mechanism analysis of fabricated friction dissipation re-centering brace with zero initial cable force," Journal of Southeast University (Natural Science Edition), vol. 47, no. 1, pp. 142-149, 2017.

[44] A. M. Girão Coelho, L. S. D. Silva, and F. S. K. Bijlaard, "Ductility analysis of bolted extended end plate beam-to-column connections in the framework of the component method," Steel and Composite Structures, vol. 6, no. 1, pp. 33-53, 2006.

[45] Li. Lm, Z. H. Chen, and N. Li, "Experimental study on seismic capability of diaphragm-through style beam-column joint," Earthquake Engineering and Engineering Vibration, vol. 27, no. 1, pp. 46-53, 2007 (Chinese). 

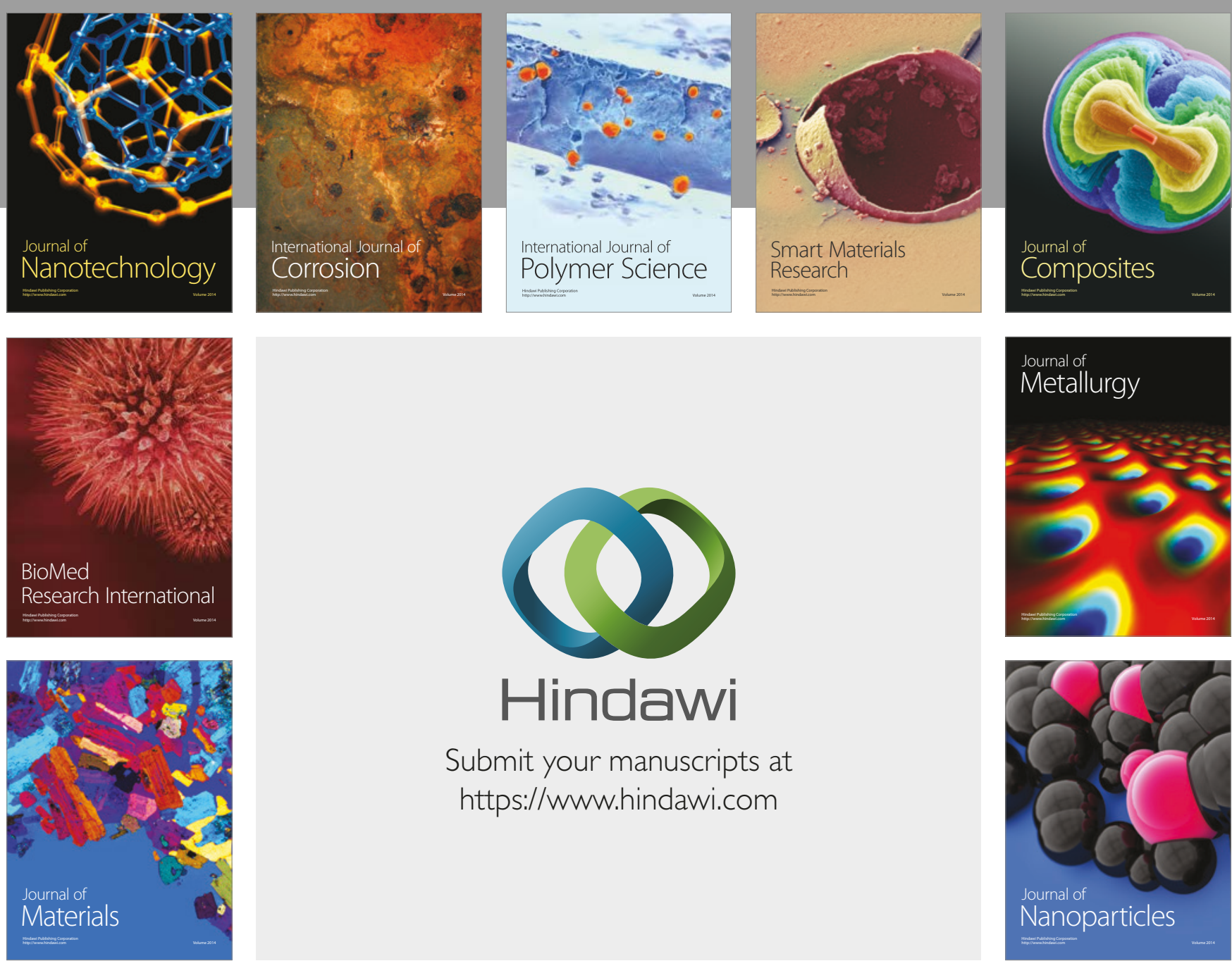

\section{Hindawi}

Submit your manuscripts at

https://www.hindawi.com
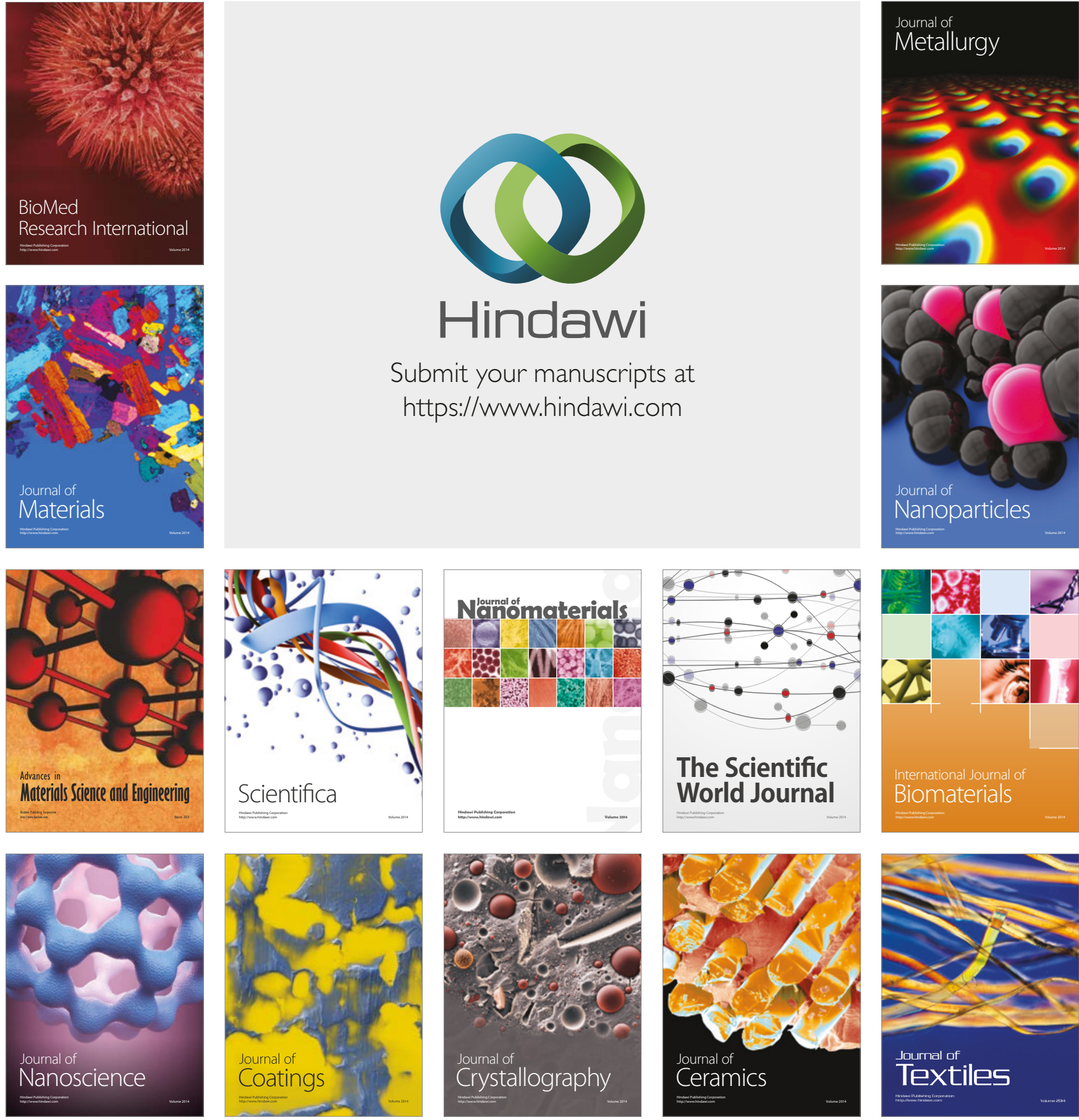

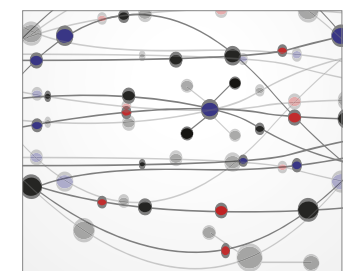

The Scientific World Journal
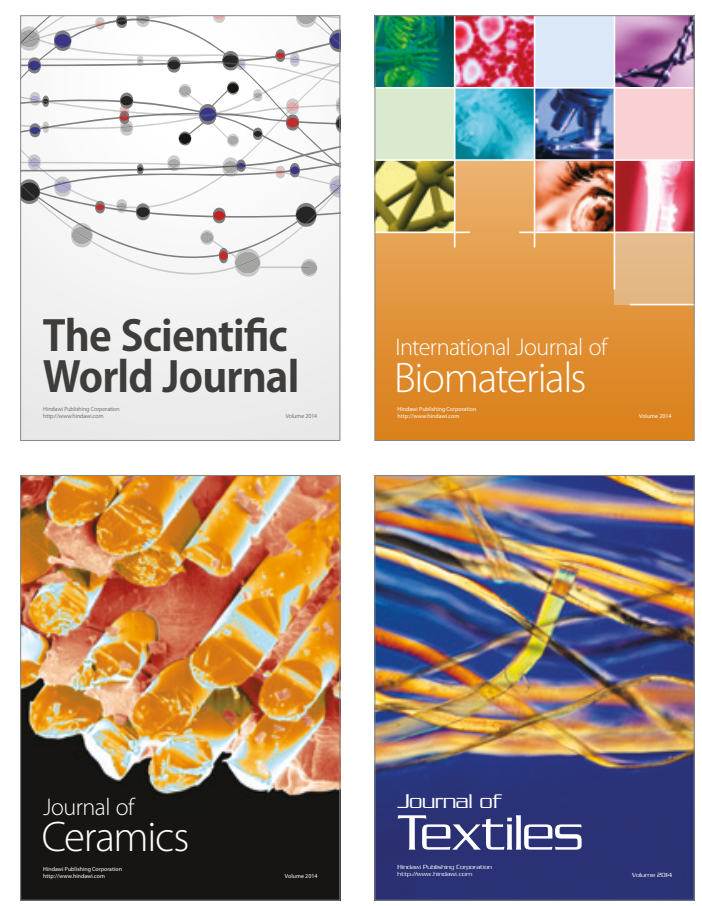